M.T. Furse, D. Hering, K. Brabec, A. Buffagni, L. Sandin \& P.F.M. Verdonschot (eds), The Ecological Status of European Rivers: Evaluation and Intercalibration of Assessment Methods DOI 10.1007/s10750-006-0067-6

\title{
The STAR project: context, objectives and approaches
}

Mike Furse ${ }^{1, *}$, Daniel Hering ${ }^{2}$, Otto Moog ${ }^{3}$, Piet Verdonschot ${ }^{4}$, Richard K. Johnson ${ }^{5}$, Karel Brabec ${ }^{6}$, Kostas Gritzalis ${ }^{7}$, Andrea Buffagni ${ }^{8}$, Paulo Pinto ${ }^{9}$, Nikolai Friberg ${ }^{10}$, John Murray-Bligh ${ }^{11}$, Jiri Kokes ${ }^{12}$, Renate Alber ${ }^{13}$, Philippe Usseglio-Polatera ${ }^{14}$, Peter Haase ${ }^{15}$, Roger Sweeting ${ }^{16}$, Barbara Bis ${ }^{17}$, Krzysztof Szoszkiewicz ${ }^{18}$, Hanna Soszka ${ }^{19}$, Gunta Springe ${ }^{20}$, Ferdinand Sporka ${ }^{21} \& \mathrm{Il}^{\prime} \mathrm{ja} \mathrm{Krno}^{22}$

${ }^{1}$ Centre for Ecology and Hydrology, CEH Dorset, Winfrith Technology Centre, Winfrith Newburgh, Dorchester, Dorset $D T 28 Z D, U K$

${ }^{2}$ Institute of Hydrology, University of Duisburg-Essen, Universitaetsstr. 5, 45117 Essen, Germany

${ }^{3}$ Institute for Hydrobiology and Aquatic Ecosystem Management, University of Natural Resources and Applied Life Sciences Vienna, Max Emanuel Strasse 17, A-1180 Vienna, Austria

${ }^{4}$ Department of Ecology and Environment, Alterra, Droevendaalsesteeg 3, 6700 AA Wageningen, The Netherlands

${ }^{5}$ Department of Environmental Assessment, Swedish University of Agricultural Sciences, P.O. Box 7050, S-750 07 Uppsala, Sweden

${ }^{6}$ Department of Zoology and Ecology, Masaryk University, Kotlárská, 61137 Brno, Czech Republic

${ }^{7}$ Hellenic Centre for Marine Research, Institute of Inland Waters, $46.7 \mathrm{~km}$ Athens-Sounion Avenue, 19013 Anavyssos, Greece

${ }^{8}$ CNR-Water Research Institute, Via della Mornera, 25 I-20047 Brugherio (Milano), Italy

${ }^{9}$ Centre of Applied Ecology, University of Evora, Apartado 94, Lago dos Colegiais 2, 7002-554 Evora, Portugal

${ }^{10}$ Department of Freshwater Ecology, NERI, National Environmental Research Institute, Vejlsøvej 25, P.O. Box 314, DK-8600 Silkeborg, Denmark

${ }^{11}$ South West Region, Manley House, Kestrel Way, Environment Agency, EX2 7LQ Exeter, Devon, UK

${ }^{12}$ Vyzkumny Ustav Vodohospodarsky T.G. Masayka, Drevarska 12, 65757 Brno, Czech Republic

${ }^{13}$ LABBIO, Unterbergstrasse 2, 39055 Laives, Italy

${ }^{14}$ Centre of Ecotoxicology, Biodiversity and Environmental Health, University of Metz, Campus Bridoux, Rue de Général, 57070 Metz, France

${ }^{15}$ Senckenbergische Naturforschende Gesellschaft, Lochmuehle 2, D-63599 Biebergemünd, Germany

${ }^{16}$ Freshwater Biological Association, The Ferry House, Far Sawrey, LA22 0LP Cumbria, UK

${ }^{17}$ Institute of Ecology and Nature Protection, Department of Applied Ecology, University of łodź, Banacha 12/16, 90-237 łodź, Poland

${ }^{18}$ Department of Ecology and Environmental Protection, Agricultural University of August Cieszkowski, ul. Piatkowska 94C, 61-691 Poznan, Poland

19 Lake Protection Laboratory, Instytut Ochrony Środowiska, Kolektorska 4, 01-692 Warsaw, Poland

${ }^{20}$ Institute of Biology, University of Latvia, Miera 3, 2169 Salaspils, Latvia

${ }^{21}$ Institute of Zoology, Department of Hydrobiology, Slovak Academy of Sciences, Dubravska cesta 9 , 84206 Bratislava, Slovakia

${ }^{22}$ Faculty of Science, Department of Ecology, Comenius University Bratislava, Mlynská dolina B-2, 842 15 Bratislava, Slovakia

(*Author for correspondence: E-mail: mtf@ceh.ac.uk)

Key words: Water Framework Directive, ecological status, biological quality elements, intercalibration, uncertainty, software

\section{Abstract}

STAR is a European Commission Framework V project (EVK1-CT-2001-00089). The project aim is to provide practical advice and solutions with regard to many of the issues associated with the Water 
Framework Directive. This paper provides a context for the STAR research programme through a review of the requirements of the directive and the Common Implementation Strategy responsible for guiding its implementation. The scientific and strategic objectives of STAR are set out in the form of a series of research questions and the reader is referred to the papers in this volume that address those objectives, which include: (a) Which methods or biological quality elements are best able to indicate certain stressors? (b) Which method can be used on which scale? (c) Which method is suited for early and late warnings? (d) How are different assessment methods affected by errors and uncertainty? (e) How can data from different assessment methods be intercalibrated? (f) How can the cost-effectiveness of field and laboratory protocols be optimised? (g) How can boundaries of the five classes of Ecological Status be best set? (h) What contribution can STAR make to the development of European standards? The methodological approaches adopted to meet these objectives are described. These include the selection of the 22 stream-types and 263 sites sampled in 11 countries, the sampling protocols used to sample and survey phytobenthos, macrophytes, macroinvertebrates, fish and hydromorphology, the quality control and uncertainty analyses that were applied, including training, replicate sampling and audit of performance, the development of bespoke software and the project outputs. This paper provides the detailed background information to be referred to in conjunction with most of the other papers in this volume. These papers are divided into seven sections: (1) typology, (2) organism groups, (3) macrophytes and diatoms, (4) hydromorphology, (5) tools for assessing European streams with macroinvertebrates, (6) intercalibration and comparison and (7) errors and uncertainty. The principal findings of the papers in each section and their relevance to the Water Framework Directive are synthesised in short summary papers at the beginning of each section. Additional outputs, including all sampling and laboratory protocols and project deliverables, together with a range of freely downloadable software are available from the project website at www.eu_star.at.

\section{Context}

\section{The Water Framework Directive}

Europe has a hundred years of experience of using biological assemblages to assess the condition of streams and rivers. The first procedures were developed early in the 20th century in central Europe and were based on the concept of saprobity (Sladecek, 1973). Saprobic systems varied in their design and application but could use both micro- and macroscopic plant and animal communities in order to evaluate sites. A wide diversity of techniques blossomed throughout the 20th century (Hellawell, 1978, 1986) and, whilst a range of different biological groups continued to be used, the use of benthic macroinvertebrates became by far the commonest approach (Metcalfe, 1989; Metcalfe-Smith, 1994). Each country or, sometimes, region of a country tended to develop their own methodological procedures (Knoben et al., 1995). These incorporated a common internal approach to sampling, sample processing, indexation and quality classifications (Birk \& Hering, 2002).

Whilst a range of specific monitoring traditions was evolving in individual states, the formation of the European Union resulted in a growing convergence of the legislative infrastructure of its Member States and the strategies adopted to implement this legislation. The mechanism commonly used to implement common community practices has been the issue of a directive from the European parliament. In the 1990's pressure grew for the rationalisation of these 'water quality' directives into a single overarching directive to meet this objective (Mandl, 1992). The resultant directive, commonly known as the Water Framework Directive or WFD, was published in 2000 (European Commission, 2000).

Significantly, the directive embraced the concept of the 'Reference Condition' (Hughes, 1995) as a unifying concept for aiding the harmonization of results obtained in a variety of different 
countries/regions using a variety of their own 'traditional' assessment protocols. This concept had already been applied successfully in the United Kingdom through the development and application of RIVPACS (Wright et al., 1989, 2000) and had subsequently been taken up outside Europe in Australia (Norris, 1994) and Canada (Reynoldson et al., 1995, 2000; Rosenberg et al., 2000).

The WFD recognised type specific biological reference conditions based on a physical and chemical typology of surface water bodies in each European eco-region sensu Illies (1978). For this purpose Member States were expected to develop a reference network for each stream type containing a sufficient number of sites of high ecological status to provide a sufficient level of confidence about the values for the reference condition.

The term 'Ecological Status' was the overarching term coined by the WFD to represent the 'quality of the structure and functioning of aquatic ecosystems associated with surface waters'. Five categories of Ecological Status are recognised by the directive; High, Good, Moderate, Poor and Bad. The WFD provides normative definitions of the biological community structure associated with the High, Good and Moderate status classes. (European Commission, 2000). Member States are required to implement programmes of measures in order that all surface water bodies achieve at least 'good Ecological Status' within a defined timetable.

Whereas only macroinvertebrate data were required for the application of most prediction and assessment systems, the WFD required the sampling and interpretation of data on a broader suite of 'biological quality elements' (BQEs). These included phytoplankton, other aquatic flora, macroinvertebrates and fish. Parameters to be considered for each element are the composition and abundance of its biotic assemblages. In addition the age structure of fish populations shall be taken into consideration.

In common with systems such as RIVPACS (Wright et al., 2000), the WFD required that observed metric values for BQEs in a water body undergoing monitoring were mathematically compared with expected values for reference condition sites based on predictive modelling, hindcasting or expert judgement. The WFD presumed that the ratios so-calculated would be in the range $0-1$ and the numerical value derived by such a comparison was termed the Ecological Quality Ratio (EQR). The division of the value range of an EQR into classes provides a mechanism for categorising the ecological status of sites.

The precise BQEs to be monitored will be dependant on the type of monitoring to be undertaken. The WFD recognises three forms of monitoring: surveillance (to provide an assessment of the overall surface water status within each catchment), operational (to establish the status of water bodies identified as being at risk of failing to meet environmental objectives) and investigative (the source and magnitude of a specific pollutant). In surveillance monitoring, parameters indicative of all biological elements shall be monitored except where it is not possible to establish reference conditions for a particular element due to that element's high degree of natural variability in the water body being monitored. In contrast, operational and investigative monitoring may be restricted to one or two BQEs.

In addition to the direct monitoring of the biological assemblages, the other quality elements to be monitored for the classification of Ecological Status comprise hydromorphological, chemical and physiochemical elements supporting the biological elements.

\section{Common Implementation Strategy}

The WFD sets the framework for future monitoring of surface waters and sets out the mechanisms for reporting on the results of monitoring programmes and the formulation of river basin management plans, based upon the information gathered by monitoring and other sources. However, it is not prescriptive of the methodologies to be used to collect and process biological samples nor the specific metrics or multi-metrics to be used to calculate the Ecological Quality Ratios or the class value limits of these EQRs for each of the five classes of Ecological Status. It also provides no specific guidance on how the results of monitoring of the many and diverse quality elements shall be integrated in order to provide a single classification of the water body's status nor on how estimates of the required level of confidence and precision should be made. 
For these reasons (European Commission, 2001), a Common Implementation Strategy (CIS) was established in order to develop common understanding of the technical and scientific implications of the directive and, in so doing, to achieve its harmonised implementation. Amongst the many guidance documents emanating from CIS working groups are reports on the establishment of the Intercalibration Network and on the intercalibration exercise (European Commission, 2002), on establishing reference conditions and ecological status class boundaries (European Commission, 2003a), on monitoring for the WFD (European Commission, 2003b) and on the overall approach to the classification of Ecological Status (European Commission, 2003c).

A series of Geographical Intercalibration Groups (GIGS) have been set up to agree on the intercalibration strategy to be adopted in discrete geographical areas of the European Union. Fifteen GIGS have been established including five river groups for the regions Mediterranean, Central, Alpine, Eastern Continental and Northern. A defined number of countries comprise each GIG but individual countries may belong to more than one GIG if the variation in the river types within its borders qualifies it to do so.

\section{Supportive European Commission} research projects

\section{$A Q E M$}

In support of the technical activities associated with the implementation of the WFD, the European Union has commissioned a series of research projects designed to provide scientific support for the technical processes. The first of these projects specifically concerned with the assessment of Ecological Status was the AQEM project (EVK1CT1999-00027). The structure and objectives of the project and the main scientific findings and applied outputs are described in a special issue of Hydrobiologia (Hering et al., 2004b).

The AQEM project established a standard macroinvertebrate sampling protocol, the AQEM method, and a common field protocol for recording hydromorphological, physical, chemical and geographical information concerning the study sites and their upstream, downstream and riparian environs (Hering et al., 2004a). Outputs of the project include a database (AQEMDip) for the orderly storage and retrieval of macroinvertebrate and environmental data and a river assessment program (now termed ASTERICS) for calculating the values of almost 200 biological metrics and selected national multi-metric systems.

Whilst the AQEM project addressed many of the key questions associated with the use of macroinvertebrate data for assessing the Ecological Status of surface waters, the directive also required the integration of other biological quality elements together with the hydromorphological, chemical and physical elements that support the biological elements.

\section{$S T A R$}

STAR is a European Commission Framework V project (EVK1-CT-2001-00089) with the full title of 'Standardisation of river classifications: Framework method for calibrating different biological survey results against ecological quality classifications to be developed for the Water Framework Directive'. The project is categorised as 'Pre-normative, co-normative research and standardisation'. It therefore seeks to provide practical solutions to some of the additional problems associated with the implementation of the directive. Issues addressed include comparison of macroinvertebrate sampling methods, the effectiveness of the use of different organism groups in different stream types and for different stressors, variation and uncertainty in the collection and interpretation of biological data, the inter-calibration of assessment methods for the allocation of Ecological Status, the formulation of drafts for the relevant CEN bodies, and the development of a decision support system to assist water managers in applying the project findings. In this paper the objectives of the STAR project and the methodological approach adopted to achieve these aims will be described. It will provide the background for the remaining papers that comprise this special issue of Hydrobiologia.

\section{$F A M E$ and $R E B E C C A$}

Clustered with the STAR project and collaborating closely with it has been another EC Framework V project, FAME (EVK1-CT-200100094). This project has developed a specific system for the assessment of the Ecological 
Status of surface waters based on the fish communities that they support (Noble \& Cowx, 2002). The STAR project is also working collaboratively with the EC Framework VI project, REBECCA (SSP1-CT-2003-502158), that aims to provide new interpretations of the relationships between Chemical and Ecological Status of surface waters in order to support the implementation of the WFD.

\section{Objectives}

The central objectives of STAR and the papers in this volume that address them are:

- Which methods or biological quality elements are best able to indicate certain stressors?

The varying responses to stressors of different biological quality elements will allow WFD monitoring data to be interpreted in a diagnostic manner in order to identify the pressures operating on aquatic systems. Advice on the selection of the most appropriate BQEs for specific objectives and in specific regions is provided by Johnson et al. (2006a, b) and Pinto et al. (2006). Other authors consider specific techniques (Kokeš et al., 2006 PERLA) or taxonomic groups and stressors (Szoszkiewicz et al., 2006b - macrophytes and organic pollution; O'Hare et al., 2006 - macrophytes and habitat alteration). In addition the application of River Habitat Survey Techniques (Raven et al., 1998) to the evaluation of the hydromorphological condition of watercourses is evaluated by Erba et al. (2006) and Szoszkiewicz et al. (2006a).

- Which method can be used on which scale?

The organism groups that the WFD require to be considered in assessing the Ecological Status of waterbodies indicate environmental change on different scales. The issue of scale has been considered by Springe et al. (2006) and Verdonschot (2006a).

- Which methods are suited for early and late warnings?

Besides the spatial dimension, different organism groups indicate change on different temporal dimensions, thus providing different signals of early or late warning. Johnson et al. (2006b) address this issue for all BQEs except phytoplankton.

- How are different assessment methods affected by errors and how can 'signal' be distinguished from 'noise'?

STAR has investigated a range of factors that confound the ability of bioassessment procedures to detect change and many papers in this volume address the issue of uncertainty. These include Besse-Lotoskaya et al. (2006) who investigate uncertainty associated with diatom sampling and interpretation, Clarke et al. (2006a, b) and Lorenz $\&$ Clarke (2006) who look at the impact of sampling variation on macro-invertebrate assessments, Haase et al. (2006) who consider the effects of macro-invertebrate sorting and identification errors; Staniszewski et al. (2006) and BaattrupPedersen et al. (2006) who examine uncertainty associated with macrophyte surveys and Johnson et al. (2006a) who explore the incidence and effects of Type I and Type II errors for most BQEs. One factor that may influence the evaluation of sites is the method used to define reference conditions. Davy-Bowker et al. (2006) consider the implications of using type specific conditions based on a physical/chemical typology with those site specific reference conditions produced by predictive systems such as RIVPACS and PERLA (Kokeš et al., 2006).

- How can data from different assessment methods and taxonomic groups be compared and intercalibrated and how can the results of the STAR programme be used to assist the WFD intercalibration exercise?

A central problem, for the implementation of the WFD, is how biological data collected using different national protocols and biological quality elements (BQEs) can be compared and integrated in order to derive comparable allocations of sites to standard European classes of environmental degradation. Friberg et al. (2006) compare the main macroinvertebrate sampling procedures used in Europe, whilst alternative mechanisms for inter-calibration are discussed by Birk \& Hering (2006 - macroinvertebrates), Birk et al. (2006 macrophytes) and Buffagni et al. (2006 - general but principally macroinvertebrates). 
- How can the cost-effectiveness of field and laboratory protocols for the collection and processing of macroinvertebrate samples be optimised?

Methodologically, standardisation must also take a balanced account of the relative costs and ecological effectiveness of different field and laboratory procedures. Experimental field studies were devised to consider a spectrum of relevant issues (Šporka et al., 2006; Vlek et al., 2006) whilst Verdonschot (2006b) examined the significance of varying levels taxonomic precision on the biological typology of European streams and rivers.

- Can species trait analysis provide a unifying procedure for the establishment of reference conditions and the assessment of Ecological Status?

An aim of STAR was to test the applicability of a species trait analysis as a unifying theme for the derivation of functionally based reference conditions and, as a result, for the assessment of Ecological Status. These results are presented elsewhere including as Deliverable N2 (Bis \& Usseglio-Polatera, 2004) on the STAR website www.eu-star.at

- How can boundaries of the five classes of Ecological Status recognised by the WFD be best set?

On the basis of the field and laboratory protocols and metrics that will be tested in STAR, an aim of the project is investigate and to elaborate standard procedures for the determination of European class boundaries of Ecological Status. Mechanisms for setting and inter-calibrating class boundaries are considered by Birk \& Hering (2006), Birk et al. (2006) and Buffagni et al. (2006).

- How can the results of the STAR programme be used to make recommendations for common European standards?

The STAR consortium have suggested outline standards, on methodological issues related to the implementation of the WFD that are being considered by CEN (Comité Européen de Normalisation) for adoption as full standards. These include multi-habitat sampling for invertebrates, the construction of multi-metric assessment systems and the selection of the best suited organism groups for specific monitoring purposes. Methodologies for developing multi-metric indices are elaborated in this volume by Hering et al. (2006). An additional standard tool for the use of the European water industry and academia is a pan-European macro-invertebrate ecological database and taxa inventory described here by Schmidt-Kloiber et al. (2006).

\section{Approaches: site selection}

\section{Research framework}

The STAR consortium comprised 22 partners from 14 countries including four countries who were candidate states, the Czech Republic, Slovakia, Poland and Latvia, that acceded to the European Union during the course of the project on 1st May 2004.

The project was divided into 19 discrete but inter-linked workpackages (Table 1). Most workpackages (WPs) could be allocated to one or other of two loose groupings. There were ten core WPs in which most partners worked collaboratively on a common activity and nine that were specific research programmes contributed to by a small minority of the partners and predominantly engaged in by a dominant leading institute (Table 1).

\section{Stream types studied}

The central components of the STAR project were the two WPs devoted to the collection of new biological, hydromorphological and other environmental data (WP7 and WP8).

WP7 (Table 1) involved the selection and monitoring of sites in two core groups of stream types (Table 2). The variables and their ranges used to define each group were those involved in the system A approach to surface water body typology given in the WFD (European Commission, 2000). Sites in core group 1 were defined as 'Small, shallow, upland streams' in early STAR project documentation. In WFD system A terms they are sites with a 'small' catchment situated in the lower $60 \%$ of the 'mid-altitude' range. Core group 2 sites were defined in early STAR 
Table 1. The 19 STAR project workpackages (WPs)

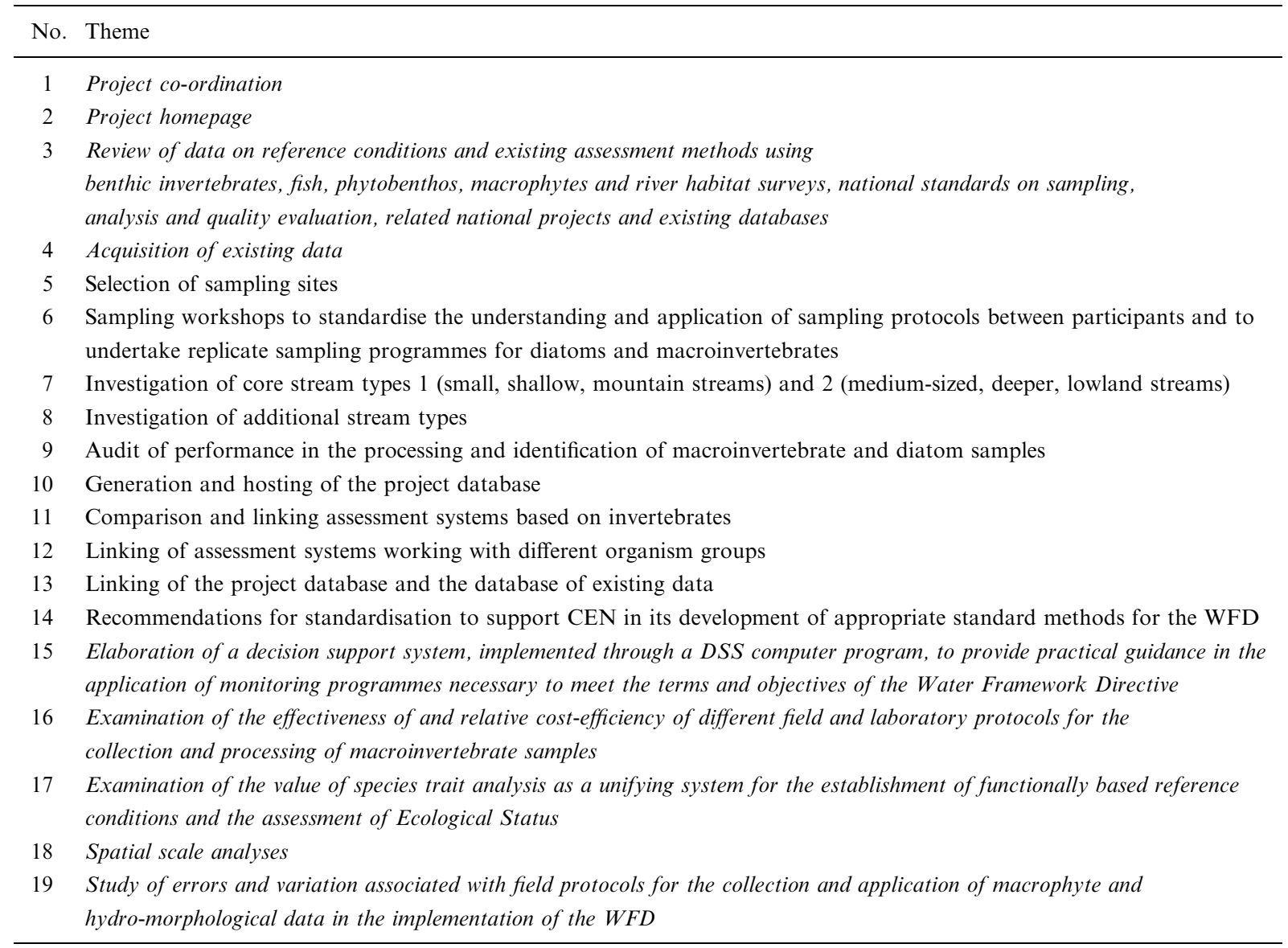

The 10 core collaborative WPs are shown in regular font.

documentation as 'Medium-sized, deeper lowland streams'. In WFD system A terms they have 'medium' catchment sizes and are situated at 'lowland' altitudes.

WP8 (Table 1) involved the selection and sampling of a group of 'additional' stream types. Additional streams types were not prescriptively allocated to any WFD system A typology and could include sites whose combination of altitude and catchment size characteristics might or might not fit the definition of either core stream type groups 1 or 2 . In general terms they were confined to either the system A mid-altitude or lowland categories and to the system A small, medium or, very occasionally, large catchment size categories. Initially the additional stream types were selected to fulfil four specific roles. These were to:

- allow new, characteristic sites of individual states to be included in the analysis;

Table 2. Definitions of the two STAR core stream type groups

\begin{tabular}{llllll}
\hline \multicolumn{2}{l}{ Core stream type } & & \multicolumn{2}{l}{ Theoretical value range of typological variables } \\
\cline { 1 - 3 } \cline { 5 - 6 } \cline { 5 - 6 } No. & Description & & Altitude & Catchment size & Geology \\
\hline 1 & Small, shallow, upland streams & & $200-500 \mathrm{~m}$ & $10-100 \mathrm{~km}^{2}$ & Calcareous or siliceous \\
2 & Medium-sized, deeper lowland streams & & $<200 \mathrm{~m}$ & $>100-1000 \mathrm{~km}^{2}$ & Calcareous, siliceous or organic \\
\hline
\end{tabular}


- provide an opportunity to extend the range of sites in existing European assessment systems;

- extend the range of sites at which the specific field methods are compared;

- provide an opportunity to test alternative sampling/assessment methods of specific importance to individual consortium Member States.

However, the data for core and additional stream types were used jointly in most analyses. Core and additional stream types could also be defined as either calcareous, siliceous or, occasionally, organic but, with a few exceptions, sites within specific site sets (see the following section) were all in the same geological category.

\section{Selection of site sets}

Each participating partner in WP7 and/or WP8 selected a minimum of one and a maximum of three sets of sites to sample. Each set of sites was in one of the three basic stream type groups (core 1, core 2 or additional) described in the previous section. Partners with two or more site sets selected these sets to be either in the same or different stream type groups. Sets of sites defined by their stream type group, eco-region or sub-eco-region and, optionally, other geographical criteria are termed 'stream types'. The definition of stream types used here is that established by the AQEM project and is "an artificially delineated but potentially ecologically meaningful entity with limited internal biotic (taxa composition) and abiotic (chemical and hydromorphological) variation and a biotic and abiotic discontinuity toward other types" (Hering et al., 2004a). Selection of specific stream types within the three stream type groups defined in the previous section took account of many of the criteria for stream typology in System B of the WFD.

In total, 22 stream types were selected for study as part of either WP7 or WP8 (Table 3). In addition, two other stream types in Italy (small-sized calcareous streams in the Southern Apennines and medium-sized calcareous streams in the Northern Apennines) and three other stream types in Greece (small-sized siliceous streams in Northern Greece, medium-sized calcareous streams in Southern Greece and small-sized siliceous streams on the Aegean Islands) were sampled for other national purposes connected with the STAR project.
For each stream type, a minimum of ten and a maximum of 24 sites were sampled (Table 4). For each stream type, sites were selected to represent a gradient of degradation usually due to a preidentified dominant stressor (Table 4). For the purpose of site selection, these dominant stressors were divided into three broad categories: organic pollution (including eutrophication), toxic pollution (including acidification) and habitat degradation. In one case, (stream type I06 - Italy) a single dominant stressor could not be identified and the category 'general' stressors was applied. In a few other cases (see Table 4) different dominant stresses applied to specific sites within a stream type and some of these only became apparent during the sampling programme.

In general, approximately $25 \%$ of sites in each site set were selected to be likely to be of 'high', $25 \%$ of 'good', $25 \%$ of 'moderate' and $25 \%$ of 'poor'/'bad' Ecological Status. The 'high' status sites were selected to represent the reference condition for their particular stream type. Reference condition sites were selected through a combination of site visits, cartographic information and information derived from new biological sampling or existing sample data held by internal (i.e. partner's own) or external (e.g. national monitoring organisations) sources. Where adequate data were available, all biological quality elements and hydromorphological and chemical quality elements were considered. However, in many cases the most important elements considered were macroinvertebrates, hydromorphology and nutrient status. In order to aid the process of reference site selection a list of criteria was developed (Table 5) based on Hering et al. (2003) but modified in response to the ongoing discussions of the REFCOND group.

In many cases, e.g. some lowland stream types or larger streams, no reference sites meeting all of the criteria above were available. For these stream types the 'best available' existing sites were selected. However, where possible, the description of reference communities of these types could be supplemented by evaluation of historical data and possibly the biotic composition of comparable stream types, e.g. streams of a similar size but located in different ecoregions.

The remaining sites, other than reference sites, were pre-classified using the same sources of information but with particular attention to 


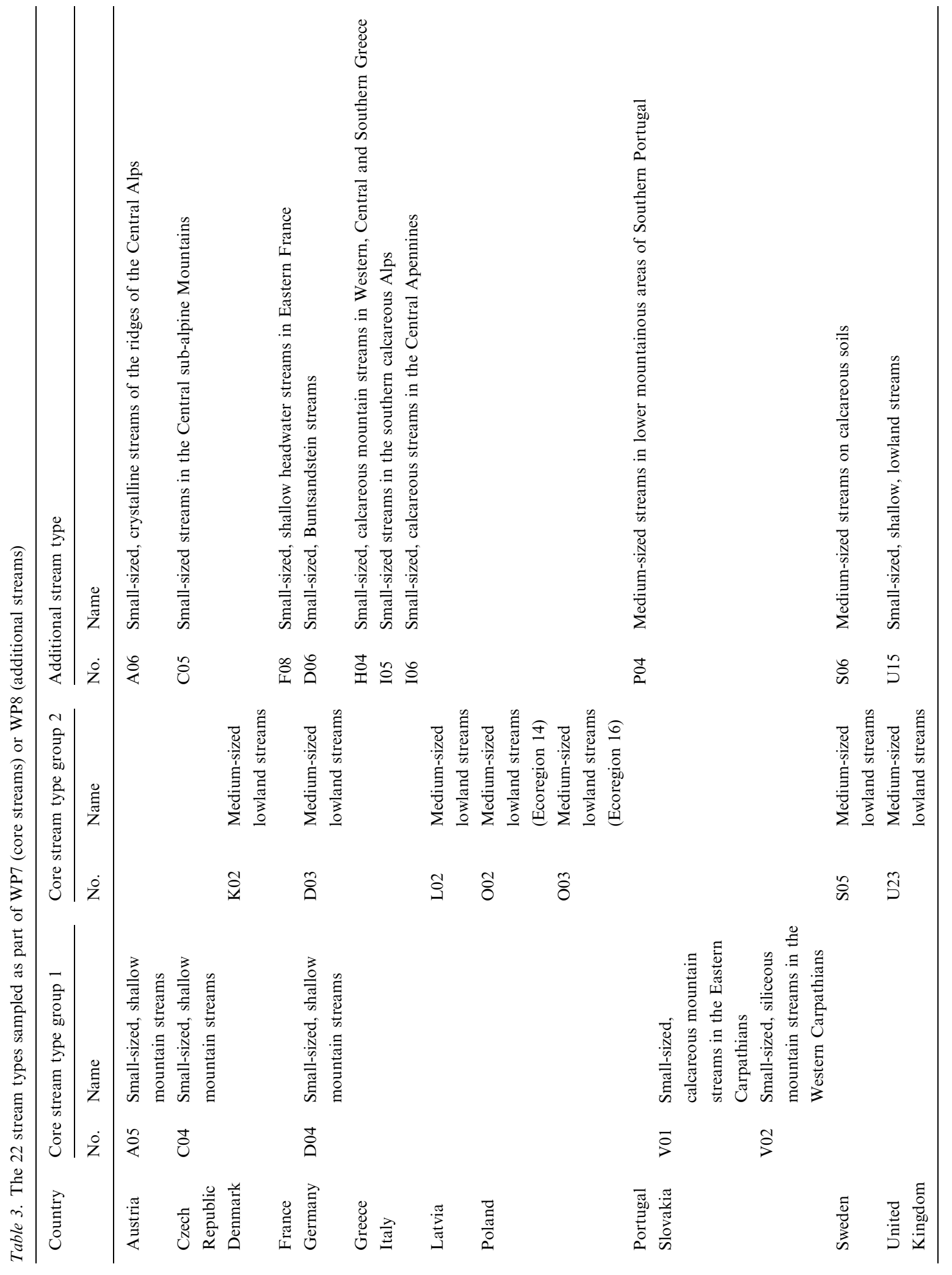




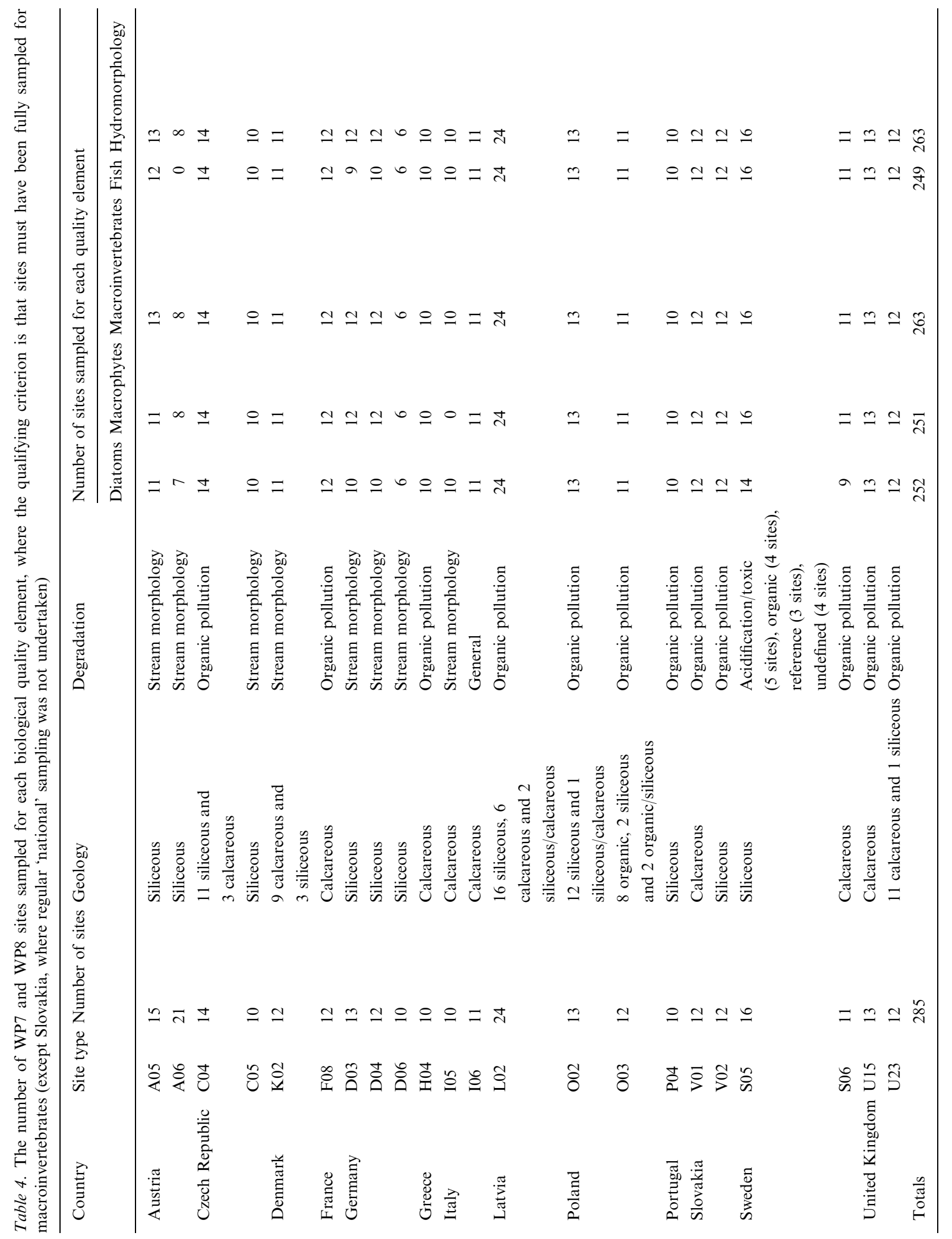


Table 5. Criteria for reference site selection

General

- The reference condition must be politically palatable and reasonable

- A reference site, or process for determining it, must hold or consider important aspects of 'natural' conditions

- The reference conditions must reflect only minimal anthropogenic disturbance

Land use practices in the catchment area

- The degree of urbanisation, agriculture and silviculture should be as low as possible for a site to serve as a reference site

- Least-influenced sites with the most natural vegetation are to be chosen

River channel and habitats

- The reference site floodplain should not be cultivated. If possible, it should be covered with natural climax vegetation and/or unmanaged forest

- Coarse woody debris should not be removed (minimum demand: presence of coarse woody debris)

- Stream bottoms and stream margins must not be fixed

- Spawning habitats for the natural fish population (e.g. gravel bars, floodplain ponds connected to the stream) should be present

- Preferably, there should be no migration barriers (affecting the bed load transport and/or the biota of the sampling site)

- In stream types in which naturally anadromous fish species would occur, the accessibility of the reference site from downstream is an important aspect for the site selection

- Only moderate influence due to flood protection measures can be accepted

Riparian vegetation and floodplain

- Natural riparian vegetation and floodplain conditions must still exist

- Lateral connectivity between the stream and its floodplain should be possible

- The riparian buffer zone should be greater or equal to $3 \times$ channel width

Hydrologic conditions and regulation

- No alterations of the natural hydrograph and discharge regime should occur

- There should be no or only minor upstream impoundments, reservoirs, weirs and reservoirs retaining sediment; no effect on the biota of the sampling site should be recognisable

- There should be no effective hydrological alterations such as water diversion, abstraction or pulse releases

Physical and chemical conditions

- No point sources of pollution or nutrient input affecting the site

- No point sources of eutrophication affecting the site

- No sign of diffuse inputs or factors which suggest that diffuse inputs are to be expected

- 'Normal' background levels of nutrient and chemical base load, which reflect a specific catchment area

- No sign of acidification

- No liming activities

- No impairments due to physical conditions

- Thermal conditions must be close to natural

- No local impairments due to chemical conditions; especially no known point-sources of significant pollution, all the while considering near-natural pollution capacity of the water body

- No sign of salinity

Biological conditions

- No significant impairment of the indigenous biota by introduction of fish, crustaceans, mussels or any other kind of plants and animals

- No significant impairment of the indigenous biota by fish farming

- No intensive management, e.g. of the fish population

Underlined criteria were mandatory and as many of the other criteria as possible were met.

reported known sources of stress as supplied by national and regional agencies with responsibility for monitoring water quality and hydromorphology.
The relative emphasis placed on individual quality elements varied from partner to partner with some placing more emphasis on biological data and less 
on hydromorphological and chemical elements than others in establishing their site pre-classification. However, each partner used their specific approach to establish a set of sites with a marked degradation gradient according to their chosen dominant stressor.

In total, excluding the Italian and Greek sites sampled for other purposes, 285 sites were selected for possible sampling for WP7 or WP8. Of these, 263 (Fig. 1) were sampled for macroinvertebrates in each sampling season using both the AQEM and, with the single exception of Slovakia, a second, mainly 'national' sampling protocol in each sampling season. These were the sites included in most of the central analyses undertaken in the project. All of these 263 sites were also subject to hydromorphological surveys and 252 were sampled for phytobenthos, 251 for macrophytes and 249 for fish. A final total of 233 were fully sampled for all biological quality elements.

\section{Selection of quality elements}

Three biological quality elements were sampled in all or almost all of the sites contributing to the central project analyses. These were 'aquatic flora', 'benthic invertebrate fauna' and 'fish fauna'. The aquatic flora was subdivided into phytobenthos and macrophytes for the purposes of this project. The only component of the flora not sampled was phytoplankton because this element was considered not to be a significant component of the biota of the small to medium-sized, often fast-flowing streams that predominated in the STAR sampling programme.

At least two survey protocols were used to record components of the hydromorphological quality element supporting the biological elements. Information on chemical and physico-chemical quality elements supporting the biological elements was, in all cases collected both from direct field sampling and surveys and also, in some cases, from data collected by the national water quality monitoring agencies.

\section{Selection of sampling reach}

Prior to starting field sampling and surveying, the study reach at each site was selected. The reach was $500 \mathrm{~m}$ long and was selected as representative of the hydromorphological conditions of the stretch of river under investigation. A stretch of river is a continuous section of river without any significant tributaries or point sources of pollution likely to modify its Chemical Status (equivalent to a 'water body' as defined by the WFD). The

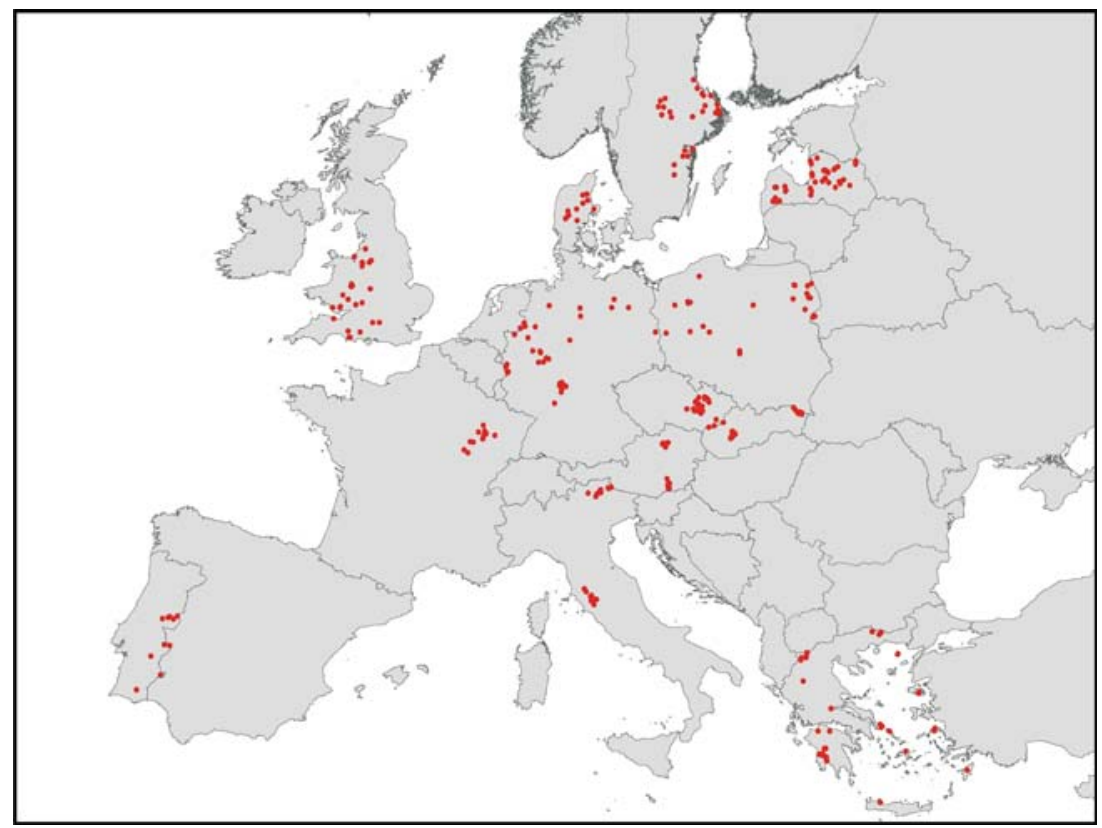

Figure 1. The location of the 263 sites sampled for macro-invertebrates. 
selection of the sampling and survey reach normally followed the completion of the AQEM site protocol (see below).

Wherever possible, at each site, a common monitoring strategy was adopted in relation to the relative positions of the different sampling/surveying points. Field surveyors were provided with a conceptual diagram of this strategy (Fig. 2).

A preliminary reach was first located and, within this, the STAR-AQEM invertebrate sampling area was selected. This was a length of river of up to $100 \mathrm{~m}$, depending on stream width (see the STAR-AQEM section below) at which all of the common representative habitat types of that river stretch were present, including both erosional ('riffle') and depositing ('pool') areas if possible. The centre of this sampling length was taken to be River Habitat Survey (RHS) spot check 9 (Raven et al., 1998) and was used to define the exact position of the whole $500 \mathrm{~m}$ RHS survey reach.

The 'national' invertebrate sampling and the phytobenthos sampling were undertaken in the same $100 \mathrm{~m}$ section as the STAR-AQEM method. Care was taken to minimise the disturbance to the river by each sampling method and overlap between the different precise sampling locations.

The macrophyte survey was undertaken in the $100 \mathrm{~m}$ reach immediately upstream of the invertebrate and diatom sampling reach and after these elements had been sampled. Where all three elements were sampled on the same day this spatial separation and sequence of sampling was designed to minimise any trampling of plants resulting from the sampling of the other two elements.

Fish sampling took place over a $\geq 100 \mathrm{~m}$ section immediately upstream of the macrophyte survey area. Fish sampling was normally undertaken on a

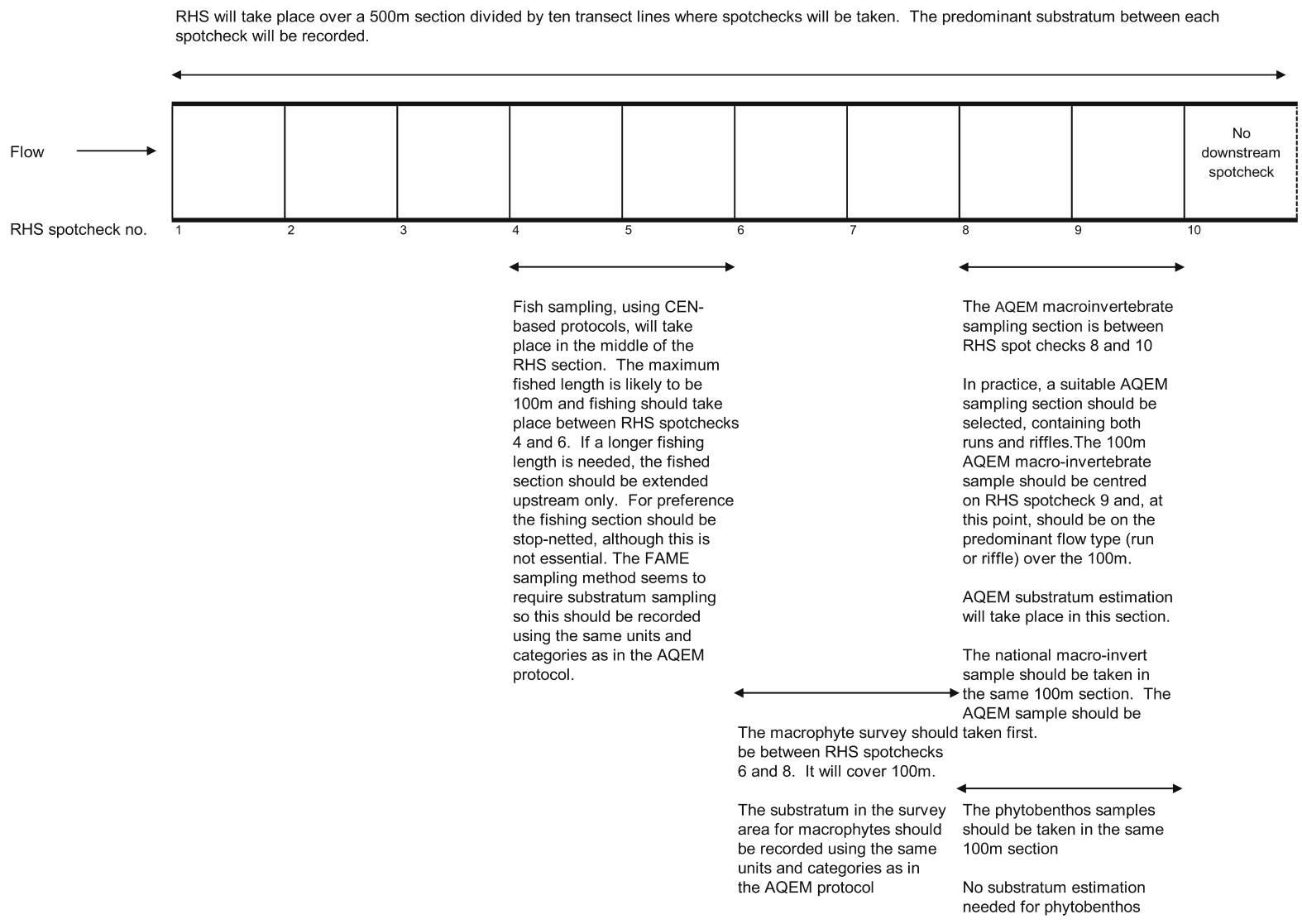

Figure 2. The conceptual locations of the STAR sampling areas for each of the five recorded quality elements at each site, as provided to field surveyors. 
separate date to the other sampling. Chemical sampling was from within this $500 \mathrm{~m}$ reach of river and avoided any disturbance to the sediment caused by biological sampling.

Whilst this strategy represented the ideal, on occasions local conditions required variations in the general pattern of sampling. Such departures from the optimal were kept to the minimum.

\section{Approaches: field and laboratory protocols}

\section{Phytobenthos - diatoms}

Diatoms were sampled once only at the WP7 and WP8 sites. Samples were collected during periods of stable stream flow and at least four weeks after a period of extreme conditions like a major storm or drought. The time of these stable conditions varied from region to region. Subject to this criterion, spring was the preferred season for sampling as diatoms dominate the phytobenthos during this season (Moore, 1977).

The location selected for STAR-AQEM invertebrate samples (Fig. 2) and the criteria for its selection, ensured that it also had the most suitable available substrata for sampling benthic diatoms. This ranged from stones to macrophytes and to mineral sediments, depending on the type of river. Selection criteria also ensured that the sampled section also combined riffles and pools and thus enabled the sampling of a good variety of natural substrata. Bank side areas were avoided during sampling with samples taken at least $10 \%$ of the river width away from the river edge.

In general terms, the sampling and processing protocols used followed those of Kelly et al. (1998) and Winter \& Duthie (2000). Methods conform to the CEN standards EN 13946 and EN 14407. The full STAR protocol for the sampling, processing and audit of diatom samples was prepared by Alterra and is available from the STAR website (www.eu-star.at).

\section{Phytobenthos - non-diatoms}

Collection of non-diatom phytobenthos was voluntary and not all partners collected information on this taxonomic group. Where partners did collect and process material they adopted the methods described in the project protocol for sampling, processing and audit of non-diatom benthic algal samples, which was also prepared by Alterra and is available from the STAR website.

\section{Macrophytes}

Macrophytes were surveyed once only at the WP7 and WP8 sites. Surveys were undertaken using a slightly adapted form of the Mean Trophic Rank (MTR) field protocol developed in the United Kingdom (Holmes et al., 1999). Most surveys were carried out between mid-June and mid-September after several days of low flow or low-normal flow as opposed to high flow/spate.

The MTR survey procedure is based on the presence and abundance of species of aquatic macrophytes, where a macrophyte is defined as 'any plant observable with the naked eye and nearly always identifiable when observed' (Holmes \& Whitton, 1977). This definition includes all higher aquatic plants, vascular cryptograms and bryophytes, together with groups of algae which can be seen to be composed predominantly of a single species.

Survey techniques conformed to the CEN standard EN 14184. The full STAR survey protocol for macrophytes (Guidance for the field assessment of macrophytes of rivers within the STAR project) was prepared for STAR by the Centre for Ecology and Hydrology and is available from the STAR website.

\section{Macroinvertebrates}

All 263 WP7 and WP8 sites listed in the macroinvertebrates column of Table 4 were sampled using a modified form of the AQEM method (AQEM consortium, 2002; Hering et al., 2004a), known as the STAR-AQEM method. With the exception of all Slovakian sites in stream type V01 and six sites in V02, all sites were also sampled using a current national method of the country (Table 6). Where no consistent national sampling method existed for the country, either the RIVPACS (Austria, Germany and Greece) or PERLA (Slovakia) methods were used instead (Table 6). With the exception of the three non-UK RIVPACS users, the national methods used were 
Table 6. 'National' sampling methods applied in each STAR country participating in project workpackages 7 and 8

\begin{tabular}{lll}
\hline Country & Methods applied & Reference \\
\hline Denmark & Danish Stream & Danish Environmental Protection Agency (1998) \\
Italy & Fauna Index (DSFI) & \\
France & Indice Biotico Esteso & Ghetti (1997) \\
& Indice Biologique & GAY, Cabinet en Environnement (1994) \\
Latvia & Global Normalisé (IBGN) & \\
Czech Republic & LVS 240:1999 & Unpublished (see 'Protocols' on www.eu-star.at) \\
Slovakia & PERLA & Kokeš et al. (2006) \\
Poland & PERLA & \\
Portugal & Polish national method & Unpublished (see 'Protocols' on www.eu-star.at) \\
Austria & Portuguese national method (PMP) & Unpublished (see 'Protocols' on www.eu-star.at) \\
& River In-Vertebrate Prediction & Murray-Bligh et al. (1997) \\
Germany & And Classification System (RIVPACS) & \\
& River In-Vertebrate Prediction & \\
Greece & And Classification System (RIVPACS) & \\
& River In-Vertebrate Prediction & \\
United Kingdom & And Classification System (RIVPACS) & \\
Sweden & River In-Vertebrate Prediction & \\
\hline
\end{tabular}

assumed to be the methods likely to be adopted by their countries for implementing the WFD.

Immediately prior to sampling, the length of river to be sampled was surveyed as part of the AQEM field protocol and the proportions of the different habitats present at the river bottom were estimated (Hering et al., 2004a). This knowledge was used to establish the precise STAR-AQEM sampling area and the proportions of micro-habitats to be sampled (Hering et al., 2004a). Normally, the STAR-AQEM sample was the first to be collected followed by the 'national' sample. For the national sample, care was taken to avoid the specific locations at which the STAR-AQEM sample was collected.

Most samples were fixed and/or preserved in the field using a fixative/preservative of the partner's choice which was normally either formaldehyde solution or ethanol of varying strength. Exceptions to this generalisation were the Italian IBE and most Latvian LVS 240:1999 samples that were sorted at the bankside, and some Portuguese 'national' samples that were sorted live in the laboratory within $48 \mathrm{~h}$ of collection. Prior to preservation and/or transport to the laboratory, large and easily identified specimens and identifiable specimens of taxa of known conservation importance or particular fragility to damage were recorded and returned live to the river.

The laboratory sample processing techniques were specific to the particular field protocols and differed between the STAR-AQEM and 'national' samples and between the different 'national' field protocols. However, all partners were trained to collect and process STAR-AQEM samples in a consistent and prescriptive manner.

In all cases taxa were identified to the best achievable level, according to the expertise of the partner and the availability of adequate national keys. Most partners achieved species level identification for most groups but this was not possible in Latvia, where only some groups could be identified to this level, nor in Greece, Italy or Portugal where most identifications were to family level.

It is not possible to describe each field and laboratory protocol here but the key features of each method are provided Friberg et al. (2006). For further details the reader is directed to the references given in Table 6, to the 'Protocols' section of the STAR website (www.eu-star.at), the AQEM website (www.aqem.de) for the key principles of the AQEM method that formed the basis 
of the STAR-AQEM procedure and to the 'Waterview' database developed during the STAR project (Birk \& Hering, 2002) and accessible via the 'Review' section of the STAR website. LVS 240:1999, the Latvian national sampling protocol (Latvian Standard Ltd., 1999) and can also be accessed via www.lvs.lv/en/services/services_EP.html.

In all cases where hand-net sampling was employed sampling and equipment specifications were consistent with CEN standard EN 27828. Where Surber sampling was used, as in the case of the French IBGN method and, occasionally, in the STARAQEM method, sampling and equipment specifications were consistent with CEN standard EN 28265.

\section{Fish}

The fishing strategy used conformed to CEN standard EN 14011 and was developed following discussions with STAR's cluster project FAME (http://fame.boku.ac.at). Almost all STAR sites were, on average, less than one metre deep and, in these circumstances, the STAR protocol was based on the section of EN 14011 relating to electric fishing of wadeable rivers.

Where possible, fishing was carried out using direct current (dc) fields. However where this was not possible, due to high conductivity water, variable electrical characteristics of stream topography or poor fish response to dc field pulsed, direct current (pdc) fields were used. In all cases, fields were adjusted to the minimum voltage gradient and current density concomitant with efficient fish capture.

Optimally, the length of river fished was a minimum of $100 \mathrm{~m}$ and located in the centre of the RHS survey area (Fig. 2). Normally the full width of the river was surveyed over this length. However, in a small minority of cases the fishing reach was slightly shorter than $100 \mathrm{~m}$ for logistical reasons (Table 7). The relative position of the fishing area within the survey area was also sometimes varied for practical reasons. Wherever possible the fishing area was demarcated by upstream and downstream stop nets (Table 7). Net mesh sizes were suitable for preventing fish $>5 \mathrm{~cm}$ from escaping. A minimum of two fishing runs was undertaken at most sites.
In the small number of cases where sites were not wadeable, fishing was undertaken from a boat (Table 7) and at a series of spot locations within the RHS survey area. In such circumstances, stop nets were not used, the sites were normally $>10 \mathrm{~m}$ wide and the length of river sampled was often less than $100 \mathrm{~m}$. Some wide, wadeable sites in Sweden were also sampled discontinuously without stop nets.

All or most of the following elements of the fish population in the sample area were recorded:

- Number of species

- Species composition (percentage of each species by number)

- Fish density by species (number of fish per $\mathrm{m}^{2}$ ) of individuals other than young of the year. There was no requirement to measure or age fish

- Young of the year per species (qualitative assessment by class, e.g. abundant, common or rare)

- Ratio between number of phytophils and limnophils (fish species grouped by reproductive guild (Balon, 1975; Mann, 1996)

- Number of intolerant or sensitive species in terms of functionally descriptive fish species (i.e., salmonids for water quality, migratory species for connectivity, etc.)

- Number of endemic species (species which are only present in the river basin under study)

- Number of native species (species known to be present in the watercourses of the country for a long period of time i.e. $>200$ years)

- Subjective assessment of degree of infestation of external parasites or other diseases

Final population estimates, capture efficiency and standard errors of population numbers were also determined. Two catch estimates were based on the Seber \& LeCren (1967) method but where more than two capture runs were undertaken values were calculated using the Exact Maximum Likelihood methodology.

\section{Hydromorphology}

At least two standard site assessment protocols, River Habitat Survey and the AQEM site protocol, were conducted at each STAR WP7 and WP8 site. Only one RHS survey was undertaken in each 


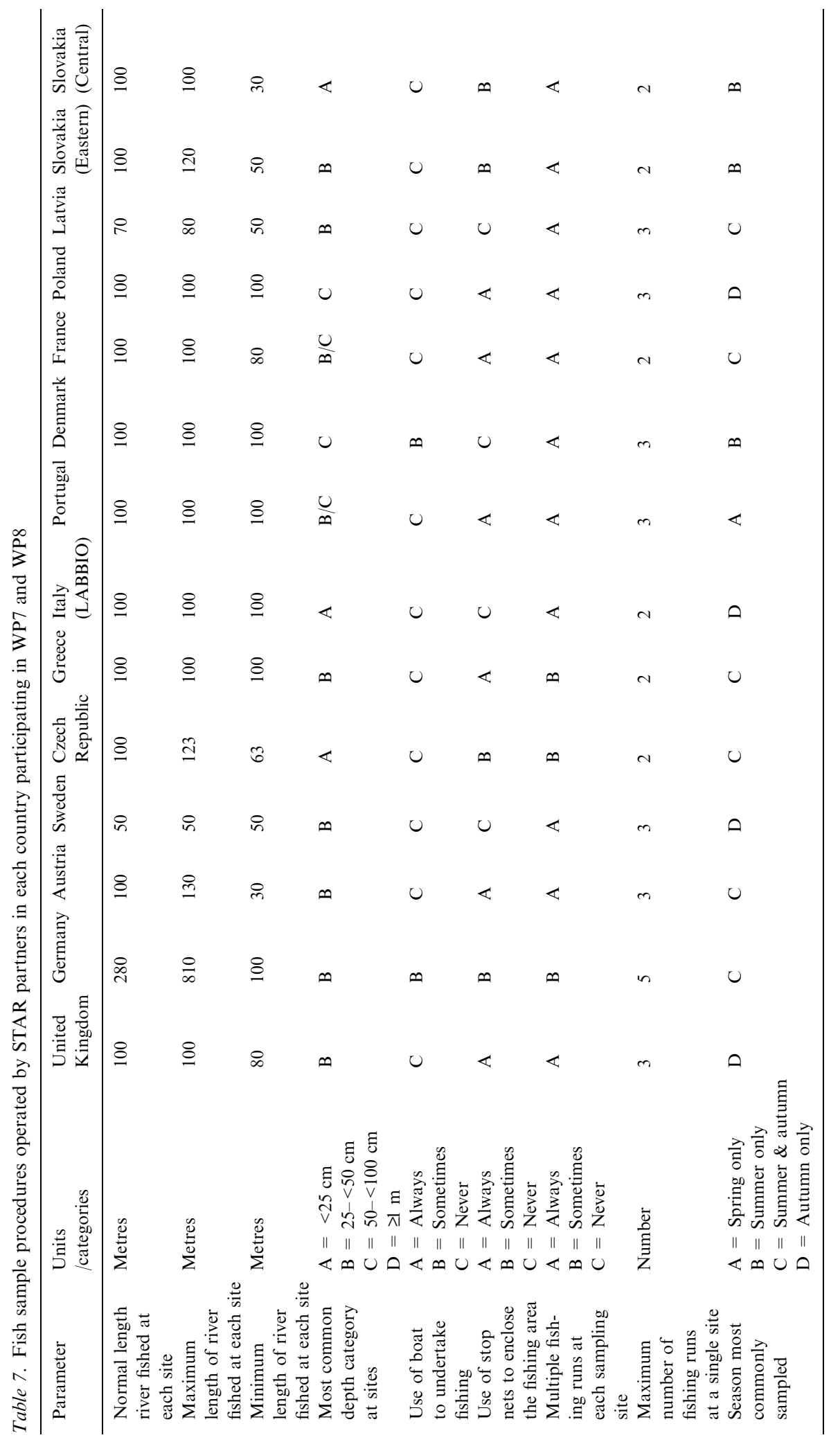


reach and normally in the period July to September. However, the AQEM site protocol comprised both time variant and time invariant variables. Time invariant variables were recorded during the first site visit only but time variant variables were recorded at the time of each macro-invertebrate sampling.

RHS is a system for assessing the quality of rivers based on their physical structure. The technique and associated interpretation comprise a standard field survey, a bespoke database and indexation systems for Habitat Quality Assessment (HQA) and Habitat Modification Score (HMS). River Habitat Survey (RHS) was developed and applied in the United Kingdom (Raven et al., 1998) but has also been applied in other European countries and has been specially adapted for use in southern Europe (Buffagni \& Kemp, 2002). The southern European modifications to the system were principally, but not exclusively, to cater for the braided channels that commonly occur there (Buffagni \& Kemp, 2002). The procedures conform to the evolving CEN standard prEN 14614.

The AQEM site protocol, as its name implies, was developed for the AQEM project and subsequently modified and simplified for the STAR project. A brief outline of the method is provided by Hering et al. (2004a) and fuller details of the original AQEM system and the modified STAR version are given on the two project websites (www.aqem.de and www.eu-star.at).

In addition separate site assessment protocols for phytobenthos, MTR and 'national' macroinvertebrate sampling were completed at most sites. Field measurements were complemented by cartographic information assembled for most of the protocols. The fish surveys were also complemented by a standard suite of site information required for the Fides database and site indexation system developed by the FAME project. These including field measurements, a broad suite of cartographic information and information on the biological, hydromorphological and chemical condition of the site collated from published data and from data supplied by national monitoring agencies.

The various site protocols adopted at STAR sites are each too complex to document in detail here and the reader is generally referred to the cited literature for a more complete understanding of the components and implementation of the RHS and AQEM site protocol techniques.

\section{Approaches: quality control and uncertainty}

A specific requirement of the WFD is that Member States support their assessments of Ecological Status of water bodies with estimates of the level of confidence and precision of the results of the monitoring programmes. The sources of uncertainty associated with results will include components resulting from each of the sampling and surveying process, the sorting of samples, identification of the sorted material, data logging and the precision of the models, hind casting or other procedures used to set the reference condition to calculate EQR values.

The assessment of many of these sources of uncertainty has been researched by Clarke (2000) and Clarke et al. $(2002,2003)$. In the STAR project, focus was on the uncertainty associated with sampling, sample sorting and the identification of specimens, where errors of data logging were considered together with identification errors.

A presumption of a well-implemented monitoring programme is that the persons responsible for carrying out each stage in the process are well trained and competent in the tasks that they are undertaking. In the STAR project partners carrying out the sampling process initially had variable experience of the tasks that they were required to perform. Even where they were experienced and proficient in parts of some tasks, such as collecting macroinvertebrates using their specific national method, they were often less well trained and experienced in collecting STAR-AQEM samples.

\section{Sampling and survey training and identification courses}

Prior to any sampling, extensive training course were arranged in the field and laboratory procedures to be used. Representatives of all partners were trained in diatom sampling and preservation, MTR procedures and River Habitat Survey. Particular emphasis was based on consistent application of the STAR-AQEM site and sampling procedures since these were the common standards against which other sampling protocols were to be 
compared. An initial week's training course in France included training sessions in sampling of diatoms, macrophytes and macroinvertebrates, including RIVPACS sampling training for the Austrian, German and Greek partners, who were using it as their 'national' method. The specialist diatom and macrophyte trainers were international experts Martyn Kelly and Nigel Holmes respectively. Macroinvertebrate sampling training was provided by highly experienced STAR internal partners.

The French training course also included the requisite three day RHS accreditation course that required all participants to pass a rigorous exam in the application of the method before they were able to undertake it in STAR. The training and accreditation was led by Helena Parsons of the UK Environment Agency.

The French course was supplemented by additional macroinvertebrate sampling training in Denmark and Poland. A separate diatom and macrophyte training course also took place in Poland and included the three day RHS training course. Additionally specialist training courses in the processing and identification of diatoms and identification courses on Oligochaeta, Plecoptera and Trichoptera were organised by expert STAR partners for other STAR partners and external scientists.

\section{Diatom ring test, replicate sampling programme} and audit

A diatom ring test was undertaken during the French training course. It was used to compare the results of simultaneous sampling of diatoms by the STAR personnel responsible for sampling this biological quality element during the main sampling programme. Parameters compared included intra- and inter-substratum variability and intraand inter-operator variability in the type and relative proportions of taxa collected and identified and the indices derived from the results of sampling.

For the ring test, samples were collected from two locations on the Plaine River, in the Vosges region of France. Samples were collected from three different habitat types; stones, macrophytes and sediments. Sampling methods followed the STAR sampling protocol (see above). Each partner collected three samples from each of two substrata at each of the two test sites. The participants who collected the samples also prepared the samples in their respective laboratories and identified and counted a minimum of 300 valves. The results of the ring test, including identification checks were evaluated by specialists at STAR partner Alterra (Besse-Lotoskaya et al., 2006).

An additional replicate sampling programme was also carried out by partners in the Czech Republic, France, Greece, Portugal, Sweden and the United Kingdom (Table 8). All samples were prepared and identified by the organisation that collected them.

All partners collecting and processing diatom samples for WP7 and/or WP8 were subject to auditing of their taxon counts and identifications. Thirty-eight percent of all core and additional stream samples were subject to audit by experts at Alterra. The samples to be re-analysed were selected randomly from all the samples taken by each partner. Therefore, all samples were numbered and the numbers of samples to be audited were selected using a list of random digits.

The identification of taxa was initially to the most precise taxonomic level that was achievable (species or variety/forma). Subsequently, following discussions amongst the STAR partners, the level of identification of some difficult taxa was made less rigorous. This provided a more consistent level of achievable identification but one that remained compatible with the metrics to be used for Ecological Status assessments. After resolving nomenclatural differences, the results of taxa and counts obtained by the primary analysts and the auditor were compared to determine the error rates (Besse-Lotoskaya et al., 2006).

\section{Macroinvertebrate replicate sampling programme and audit}

A replicate macroinvertebrate sampling programme was undertaken by all partners involved in WP7 and/or WP8 except in Slovakia. Replicate sampling was undertaken at 80 sites (Table 7). At each replicate site two STAR-AQEM samples and two national samples were collected in the same $100 \mathrm{~m}$ section of the river on the same visit in each of the two macroinvertebrate sampling 
Table 8. The number of sites subject to replicate diatom and/or macroinvertebrate sampling in the main WP7 and WP8 programmes

\begin{tabular}{|c|c|c|c|}
\hline \multirow[t]{2}{*}{ Country } & \multirow[t]{2}{*}{ Stream type } & \multicolumn{2}{|c|}{ Number of replicate sites } \\
\hline & & $\begin{array}{l}\text { Diatoms: one } \\
\text { sample per site in } \\
\text { one sampling season }\end{array}$ & $\begin{array}{l}\text { Macroinvertebrates: two } \\
\text { samples per method per site in } \\
\text { each of two sampling seasons }\end{array}$ \\
\hline \multirow[t]{2}{*}{ Austria } & A05 & 0 & 3 \\
\hline & A06 & 0 & 3 \\
\hline Czech & $\mathrm{C} 04$ & 3 & 3 \\
\hline Republic & $\mathrm{C} 05$ & 3 & 3 \\
\hline Denmark & K02 & 0 & 6 \\
\hline France & F08 & 3 & 6 \\
\hline \multirow[t]{3}{*}{ Germany } & D03 & 0 & 2 \\
\hline & D04 & 0 & 2 \\
\hline & D06 & 0 & 4 \\
\hline Greece & $\mathrm{H} 04$ & 6 & 6 \\
\hline \multirow[t]{2}{*}{ Italy } & I05 & 0 & 0 \\
\hline & I06 & 0 & 6 \\
\hline Latvia & L02 & 0 & 6 \\
\hline \multirow[t]{2}{*}{ Poland } & $\mathrm{O} 02$ & 0 & 3 \\
\hline & $\mathrm{O} 03$ & 0 & 3 \\
\hline Portugal & P04 & 6 & 6 \\
\hline \multirow[t]{2}{*}{ Slovakia } & V01 & 0 & 0 \\
\hline & V02 & 0 & 6 \\
\hline \multirow[t]{2}{*}{ Sweden } & S05 & 1 & 3 \\
\hline & S06 & 5 & 3 \\
\hline United & $\mathrm{U} 15$ & 3 & 3 \\
\hline Kingdom & $\mathrm{U} 23$ & 3 & 3 \\
\hline Totals & & 33 (33 samples) & 80 (320 samples) \\
\hline
\end{tabular}

seasons. In the case of STAR-AQEM samples, two separate blind estimates of the proportion of the habitats present were normally made and the number of sample units on each habitat in each sample was based on their respective substratum recording forms. Additional replicate sampling was undertaken at some sites as itemised by Clarke et al. (2006a, 2006b).

Sorting and processing of all main and replicate samples were undertaken by the partner collecting the samples. Each partner also conducted a separate replicate sub-sampling programme for their STAR-AQEM samples where feasible. Replicate sub-sampling was attempted on all of the 160 replicate STAR-AQEM samples. In this programme a standard STAR-AQEM sub-sample was processed for the replicate sample, involving the sorting of either five cells or the number of cells needed to obtain the $700+$ specimens required. On completion of this sub-sample a second sub-sample was processed using the material from five, or more if necessary, of the remaining cells from the sample tray grid. Replicate sub-sampling could not be undertaken in specimen-poor sites, particularly in Greece, where two sub-samples of $700+$ specimens could not be achieved.

An audit programme was undertaken involving re-sorting and re-identification of samples collected and first processed by partners. Audits were undertaken on replicate samples collected as part of the replicate sampling programme. A single replicate sample was audited for each method at each site with half the audited samples being collected in spring and half in the second sampling season. The single exception was Italy where it was only possible to audit spring samples for operational reasons. For STAR-AQEM samples the first sub-sample of the replicate sub-sampling programme was 
normally selected for auditing but occasionally the second sub-sample was audited instead.

Partners were not informed of which samples had been selected for auditing, nor that only replicate samples would be chosen, until all project samples had been processed. Prior to notification of which samples were to be audited, partners were required to provide the auditors with copies of their full taxon lists for all samples. This prevented modification of results prior to dispatching the notified samples for audit.

The audit programme was in two parts. The first part was the sorting audit to record any families of macroinvertebrates that had not been removed by the partner of origin of the sample. Representative specimens of all taxa present, including those not found by the original partner were removed from the sample and retained for further audit. Sorting audits were all undertaken by the Centre for Ecology and Hydrology except for their own samples, which were audited by the University of Duisburg-Essen.

The second stage of the audit process was the identification audit. This involved re-identification of all the taxa removed from the sample and identified by the partner of origin plus the identification of all of the additional specimens, including any new families, removed from the sample during the sorting audit process. Identification audits were shared amongst most STAR partners with the auditing partner being in the same, adjacent or similar eco-region to that of the audited partner and therefore familiar with the majority of taxa in the audited partner's region.

The output of the auditing process was a list of the families gained to samples by the sorting audit, which were genuine errors, plus a comparison of the two different lists of taxa separately identified by the audited and auditing partner. The latter differences were perceived to be differences of opinion since no arbitration or consensus of identifications were attempted. The audit therefore compared the uncertainty involved in two different experts both identifying the same set of specimens.

\section{Approaches: software development}

The project data were curated, managed and analysed using a series of bespoke database and software products developed by STAR or modified from existing software created within the AQEM project or by the Centre for Ecology and Hydrology (Table 9). The STAR website (www.eu-star.at) provided an internal discussion forum, data repository and portal to the outside world for information, ideas and reports developed during the project and the protocols used in the project for data collection. Access routes to the databases and software products in the public domain, including the Decision Support System, MONSTAR, developed as a project deliverable, are provided in Table 9.

In addition to the software developed in the STAR, AQEM and Euro-limpacs projects, phytobenthos metric values were calculated using the version 3.2 of the Omidia software (Lecointe et al., 1993). Fish data collected in the STAR project were stored and retrieved using the Fides software developed by the FAME project. Fides software was used to calculate metric values including the new European Fish Index and classification system (EFI) developed by FAME. FAME software may be accessed from http://fame.boku.ac.at/downloads.htm.

\section{Approaches: output}

STAR has been one of the central research projects contributing to the implementation of the Water Framework Directive. The STAR research programme has made significant contributions to this process through membership of, or formal advice to the Common Implementation Strategy (CIS) Working Groups, including ECOSTAT and the Geographical Inter-calibration Groups and to the Comité Européen de Normalisation (CEN) responsible for producing the methodological standards for use in conjunction with the WFD monitoring programmes.

The detailed programme of work undertaken by the group, the project deliverables, in the form of reports, data and software and much other information, including the Waterview database (Birk \& Hering, 2002) are available from the project website (www.eu-star.at). The objective of this special issue of Hydrobiologia has been to make the major findings of the project available to a wider audience via a series of individual papers. 


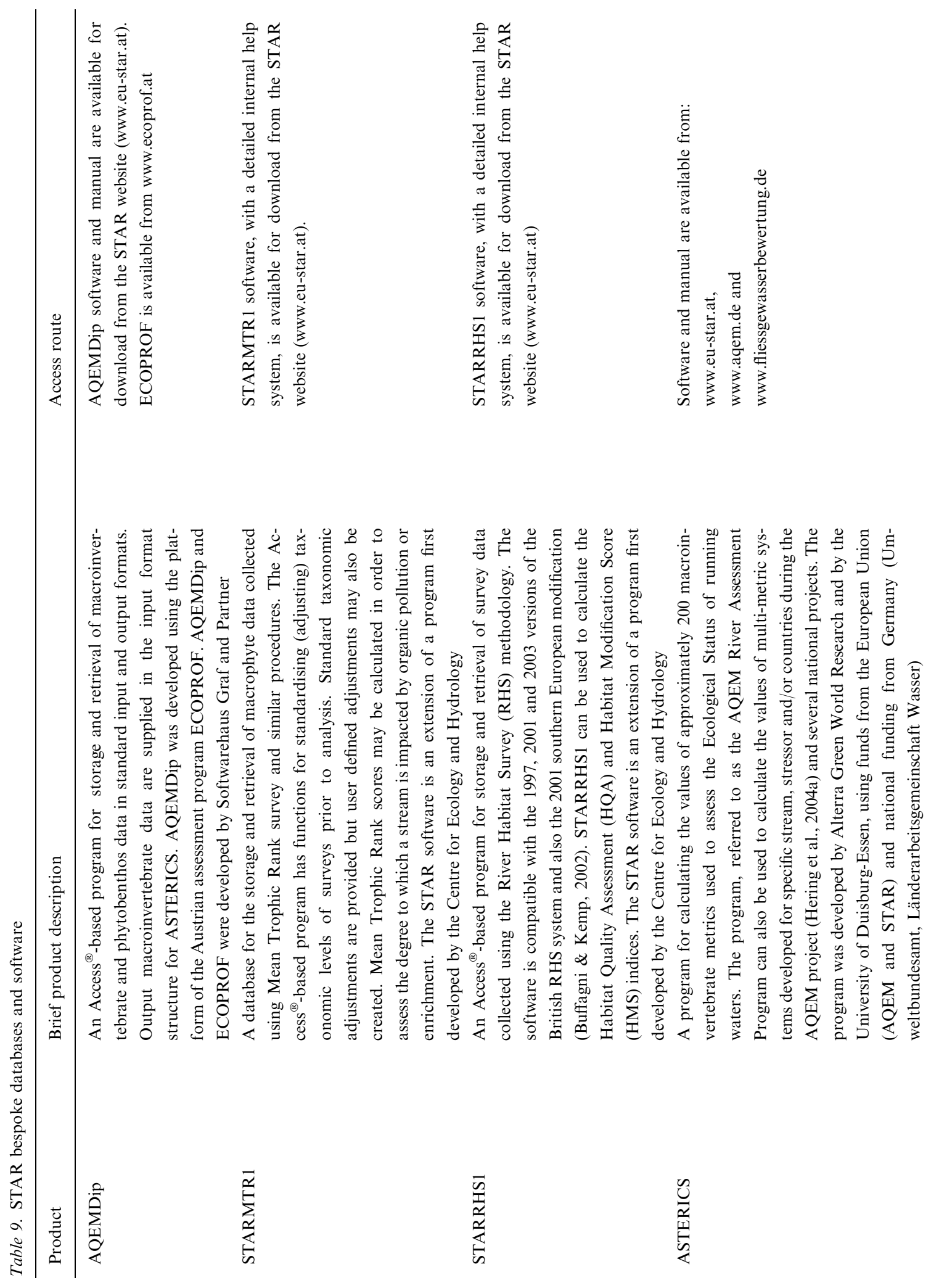




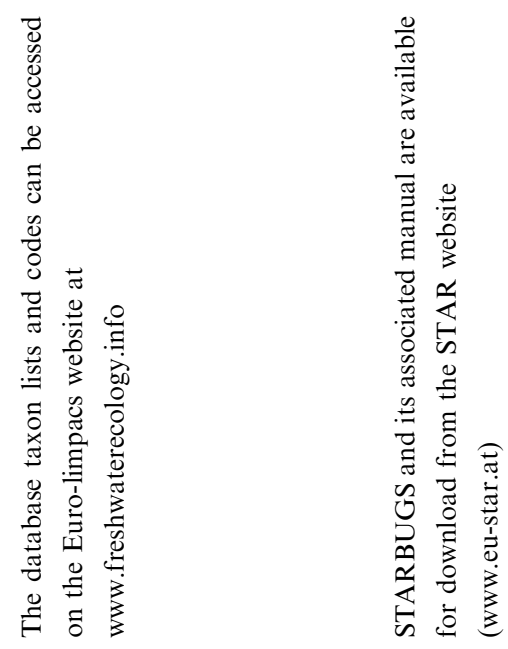

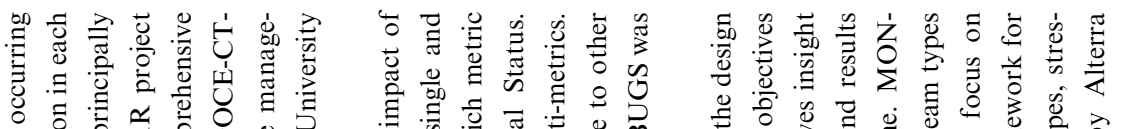

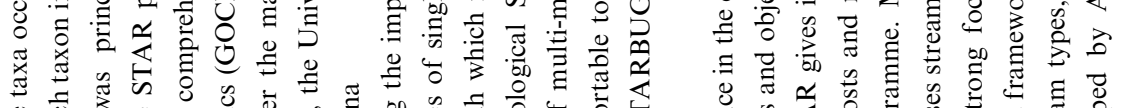

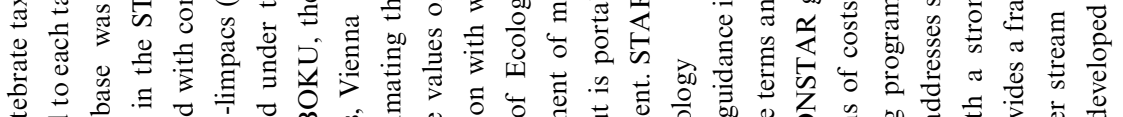

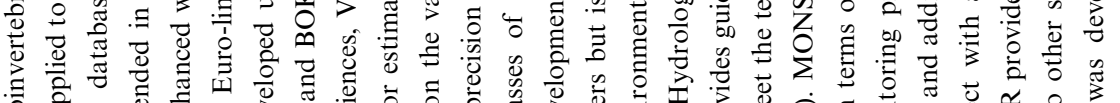

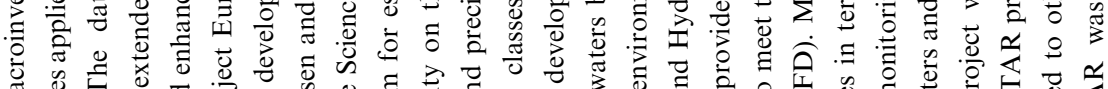

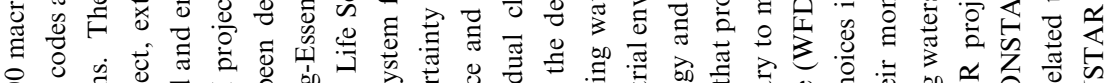

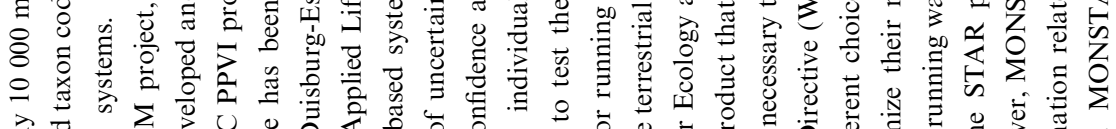

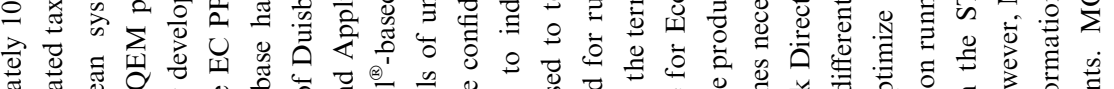

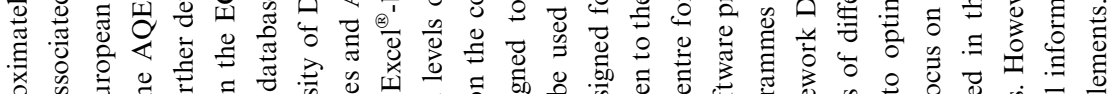

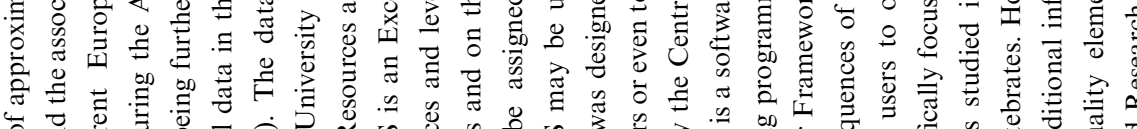

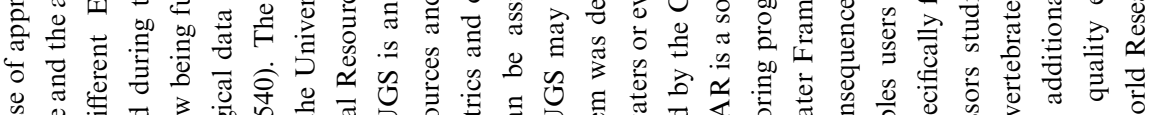

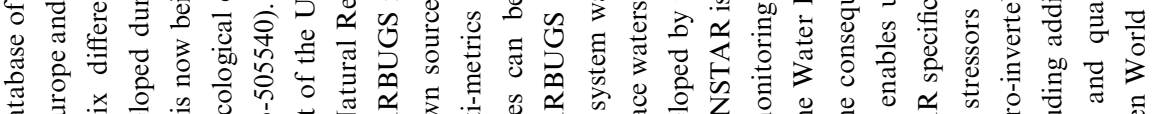

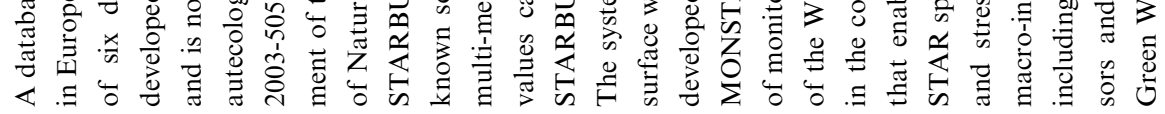

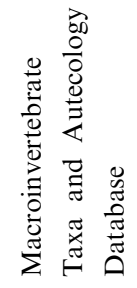

0
0
0
0
0
5 
Each of these papers directly or indirectly addresses particular practical issues faced by the CIS and by those charged with implementing the WFD. For this purpose, the volume has been divided into a series of sections devoted to specific generic issue and each comprising a set of two or more papers. The seven component sections are (1) typology, (2) organism groups, (3) macrophytes and diatoms, (4) hydromorphology, (5) tools for assessing European streams with macroinvertebrates, (6) intercalibration and comparison and (7) errors and uncertainty. This structure mirrors the sequence of practical considerations that need to be addressed in delivering a coherent monitoring programme for evaluating the Ecological Status of streams and rivers within the European Union.

The objective of this paper, as its title implies, has been to introduce the project and to set out the context, objectives and approaches taken to provide some of the scientific information needed to best implement the WFD. In doing so it provides a reference point for many of the individual papers contained within this volume and obviates the necessity to repeat this information elsewhere. In order to assimilate the key findings of the research programme, as presented here, each of the seven separate sections of this volume is prefaced by a summary paper drawing out the key results of the component papers and highlighting the recommendations of these papers and their practical contribution to the implementation process.

\section{Acknowledgements}

STAR was funded by the European Commission, 5th Framework Program, Energy, Environment and Sustainable Development, Key Action Water, contract no. EVK1-CT-2001-00089. AQEMDip and ASTERICS (formerly the AQEM River Assessment Program) were initially developed during the European Commission, 5th Framework Project AQEM, contract No. EVK1-CT199900027. ASTERICS was co-funded by Umweltbundesamt, Länderarbeitsgemeinschaft Wasser. The authors acknowledge the support of all their colleagues, too numerous to mention, who have contributed to the work described here. We are grateful to Stefan Schmutz and his colleagues in the FAME project for the use of the Fides database and their EFI software. We also wish to thank Hartmut Barth, Mogens Gadeberg and Elena Domínguez, EC Scientific Officers for STAR for their constant help and encouragement.

\section{References}

AQEM Consortium, 2002. Manual for the application of the AQEM system. A comprehensive method to assess European streams using benthic macroinvertebrates, developed for the purpose of the Water Framework Directive. Version 1.0, February 2002.

Balon, E. K., 1975. Reproductive guilds of fishes: a proposal and definition. Journal of the Fisheries Research Board of Canada 32: 821-864.

Baattrup-Pedersen, A., K. Szoszkiewicz, R. Nijboer, M. O'Hare \& T. Ferreira, 2006. Macrophyte communities in unimpacted European streams: variability in assemblage patterns, abundance and diversity. Hydrobiologia 566: 179-196.

Besse-Lotoskaya, A., P. F. M. Verdonschot \& J. A. Sinkeldam, 2006. Uncertainty in diatom assessment: Sampling, identification and counting variation. Hydrobiologia 566: 247-260.

Birk, S. \& D. Hering, 2002. Waterview Web-Database: a comprehensive review of European assessment methods for rivers. FBA News 20: 4.

Buffagni, A., S. Erba, M. Cazzola, J. Murray-Bligh, H. Soszka \& P. Genoni, 2006. The STAR common metrics approach to the WFD intercalibration process: Full application for small, lowland rivers in three European countries. Hydrobiologia 566: 379-399.

Buffagni, A. \& L. J. Kemp, 2002. Looking beyond the shores of the United Kingdom: addenda for the application of River Habitat Survey in southern European rivers. Journal of Limnology 61: 199-214.

Birk, S. \& D. Hering, 2006. Direct comparison of assessment methods using benthic macroinvertebrates: a contribution to the EU Water Framework Directive intercalibration exercise. Hydrobiologia 566: 401-415.

Birk, S., T. Korte \& D. Hering, 2006. Intercalibration of assessment methods for macrophytes in lowland streams: direct comparison and analysis of common metrics. Hydrobiologia 566: 417-430.

Bis, B. \& P. Usseglio-Polatera, 2004. Species traits analysis. STAR deliverable N2 to the European Commission, 148 pp.

Clarke, R. T., 2000. Uncertainty in estimates of river quality based on RIVPACS. In Wright, J. F., D. W. Sutcliffe \& M. T. Furse (eds), Assessing the Biological Quality of Freshwaters: RIVPACS and Similar Techniques. Freshwater Biological Association, Ambleside, 39-54.

Clarke, R. T., J. Davy-Bowker, L. Sandin, N. Friberg, R. K. Johnson \& B. Bis, 2006a. Estimates and comparisons of the effects of sampling variation using 'national' macroinvertebrate sampling protocols on the precision of metrics used to assess ecological status. Hydrobiologia 566: 477-503.

Clarke, R. T., M. T. Furse, R. J. M. Gunn, J. M. Winder \& J. F. Wright, 2002. Sampling variation in macroinvertebrate 
data and implications for river quality indices. Freshwater Biology 47: 1735-1751.

Clarke, R. T., A. Lorenz, L. Sandin, A. Schmidt-Kloiber, J. Strackbein, N. T. Kneebone \& P. Haase, 2006b. Effects of sampling and sub-sampling variation using the STARAQEM sampling protocol on the precision of macroinvertebrate metrics. Hydrobiologia 566: 441-459.

Clarke, R. T., J. F. Wright \& M. T. Furse, 2003. RIVPACS models for predicting the expected macroinvertebrate fauna and assessing the ecological quality of rivers. Ecological Modelling 160: 219-233.

Danish Environmental Protection Agency, 1998. Biological Assessment of Watercourse Quality. Guidelines, No. 5. Danish Environmental Protection Agency, Ministry of Environment and Energy, Copenhagen.

Davies, P. E., 2003. Development of a national river bioassessment system (AUSRIVAS) in Australia. In Wright, J. F., D. W. Sutcliffe \& M. T. Furse (eds), Assessing the Biological Quality of Freshwaters: RIVPACS and Similar Techniques. Freshwater Biological Association, Ambleside, 113-124.

Davy-Bowker, J., R. T. Clarke, R. K. Johnson, J. Kokes, J. F. Murphy \& S. Zahrádková, 2006. A comparison of the European Water Framework Directive physical typology and RIVPACS-type models as alternative methods of establishing reference conditions for benthic macroinvertebrates. Hydrobiologia 566: 91-105.

Erba, S., A. Buffagni, N. Holmes, M. O'Hare, P. Scarlett \& A. Stenico, 2006. Preliminary testing of River Habitat Survey features for the aims of the WFD hydro-morphological assessment: an overview from the STAR Project. Hydrobiologia 566: 281-296.

European Commission, 2000. Directive of the European Parliament and of the Council 2000/60/EC establishing a framework for Community action in the field of water policy. European Commission PE-CONS 3639/1/00 REV 1, Luxembourg.

European Commission, 2001. Common implementation strategy for the Water Framework Directive (2000/60/EC). Strategic document as agreed by the Water Directors under Swedish presidency, 2 May 2001. European Commission, 81 pp.

European Commission, 2002. Water Framework Directive (WFD) Common Implementation Strategy Working Group 2.5. Intercalibration: Towards a guidance on establishment of the intercalibration network and on the process of the intercalibration exercise. European Commission, $50 \mathrm{pp}$.

European Commission, 2003a. Water Framework Directive (WFD) Common Implementation Strategy Working Group 2.3 Reference conditions for inland surface waters (REFCOND). Guidance on establishing reference conditions and Ecological Status class boundaries for inland surface waters. Final version, 30 April 2003. European Commission, 86 pp.

European Commission, 2003b. Water Framework Directive Common Implementation Strategy Working Group 2.7 Monitoring. Guidance on monitoring for the Water Framework Directive. Final version. 23 January 2003. European Commission, $170 \mathrm{pp}$.

European Commission, 2003c. Water Framework Directive Common Implementation Strategy Working Group 2.A Ecological Status (ECOSTAT). Overall approach to the classification of Ecological Status and Ecological Potential. European Commission, 86 pp.

GAY, Cabinet en Environnement, 1994. Indice Biologique Global Normalisé. NF T 90-350. Guide Technique. Agences de l'eau et Ministère de l'Environnement, Paris.

Friberg, N., L. Sandin, M. T. Furse, S. E. Larsen, R. T. Clarke \& P. Haase, 2006. Comparison of macroinvertebrate sampling methods in Europe. Hydrobiologia 566: 365-378.

Ghetti, P. E., 1997. Manuale di Applicazione. Indice Biotico Esteso (I. B. E.). I Macroinvertebrati Nell Contro uo Della Qualita Degli Ambienti di Acquae Correnti. - Provinzia Autonoma di Trento, Agenzia Provinciale per la Protezione dell'Ambiente, Trento.

Haase, P., J. Murray-Bligh, S. Lohse, S. Pauls, A. Sundermann, R. Gunn \& R. Clarke, 2006. Assessing the impact errors in sorting and identifying macroinvertebrate samples. Hydrobiologia 566: 505-521.

Hellawell, J. M., 1978. The Biological Surveillance of Rivers: A Biological Monitoring Handbook. Water Research Centre, Stevenage.

Hellawell, J. M., 1986. Biological Indicators of Freshwater Pollution and Environmental Management. Pollution Monitoring Series. Elsevier Applied Science, London, New York.

Hering, D., A. Buffagni, O. Moog, L. Sandin, M. Sommerhäuser, I. Stubauer, C. Feld, R. K. Johnson, P. Pinto, N. Skoulikidis, P. F. M. Verdonschot \& S. Zahrádková, 2003. The development of a system to assess the ecological quality of streams based on macroinvertebrates - design of the sampling programme within the AQEM project. Internationale Revue der gesamten Hydrobiologie 88: 345-361.

Hering D., C. K. Feld, O. Moog \& T. Ofenböck, 2006. Cook book for the development of a Multimetric-Index for biological condition of aquatic ecosystems: experiences from the European AQEM and STAR projects and related initiatives. Hydrobiologia 566: 311-324.

Hering, D., O. Moog, L. Sandin \& P. F. M. Verdonschot, 2004a. Overview and application of the AQEM assessment system. Hydrobiologia 516: 1-21.

Hering, D., P. F. M. Verdonschot, O. Moog \& L. Sandin (eds), 2004b. Integrated assessment of running waters in Europe. Hydrobiologia. 516 pp.

Holmes, N. T. H., J. R. Newman, S. Chadd, K. J. Rouen, L Sharp \& F. H. Dawson, 1999. Mean Trophic Rank: A Users' Manual. R\&D Technical Report No. E38, Environment Agency, Bristol.

Holmes, N. T. H. \& B. A. Whitton, 1977. Macrophytic vegetation of the River Swale, Yorkshire. Freshwater Biology 7: 545-558.

Hughes, R. M., 1995. Defining acceptable status by comparing with reference conditions. In Davis, W. S. \& T. P. Simon (eds), Biological Assessment and Criteria. Tools for Water Resource Planning and Decision Making. Lewis Publishers, Boca Raton, FL, 31-47.

Illies, J. (ed.), 1978. Limnofauna Europaea, 2nd edn. Gustav Fischer Verlag, Stuttgart, New York; Swets and Zeitlinger B. V., Amsterdam.

Johnson, R. K., D. Hering, M. T. Furse \& R. T. Clarke, 2006a. Detection of ecological change using multiple organism groups: metrics and uncertainty. Hydrobiologia 566: 115-137. 
Johnson, R. K., D. Hering, M. T. Furse \& P. F. M. Verdonschot, 2006b. Indicators of ecological change: comparison of the early response of four organism groups to stress gradients. Hydrobiologia 566: 139-152.

Kelly, M. G., A. Cazaubon, E. Coring, A. Dell'Uomo, L. Ector, B. Goldsmith, H. Guasch, J. Hürlimann, A. Jarlman, B. Kawecka, J. Kwandrans, R. Laugaste, E.-A. Lindstrøm, M. Leitao, P. Marvan, J. Padisák, E. Pipp, J. Prygiel, E. Rott, S. Sabater, H. van Dam \& J. Vizinet, 1998. Recommendations for the routine sampling of diatoms for water quality assessments in Europe. Journal of Applied Phycology 10: 215-224.

Knoben, R. A. E., C. Roos \& M. C. van Oirschot, 1995. Biological assessment methods for watercourses. UN/ECE Task Force on Monitoring and Assessment, $86 \mathrm{pp}$.

Kokeš, J., S. Zahrádková, D. Němejcová, J. Hodovský, J. Jarkovský \& T. Soldán, 2006. The PERLA system in the Czech Republic: a multivariate approach for assessing the ecological status of running waters. Hydrobiologia 566: $343-$ 354.

Latvian Standard Ltd., 1999 LVS 240:1999 Water quality operative evaluation biological quality of small stream by saprobity index of macrozoobenthos community. In Catalogue of Latvian standards, Riga, Latvian Standard Ltd, 1999: Group 13.060, 1(11)-11.

Lecointe, C., M. Coste \& J. Prygiel, 1993. "OMNIDIA" software for taxonomy, calculation of diatom indices and inventories management. Hydrobiologia 269/270: 509-513.

Lorenz, A. \& R. T. Clarke, 2006. Sample coherence - a field study approach to assess similarity of macroinvertebrate samples. Hydrobiologia 566: 461-476.

Mandl, V., 1992. Draft EC directive on ecological quality of surface waters. In Newman, P. J., M. A. Piavaux \& R. A. Sweeting (eds), River Water Quality. Ecological Assessment and Control. Publication EUR 14606 EN-FR. Commission of the European Communities, Luxembourg, 18.

Mann, R. H. K., 1996. Environmental requirements of European non-salmonid fish in rivers. Hydrobiologia 323: 223235 .

Metcalfe, J. L., 1989. Biological water quality assessment of running waters based on macroinvertebrate communities: history and present status in Europe. Environmental Pollution 60: 101-139.

Metcalfe-Smith, J. L., 1994. Biological water quality assessment of rivers: use of macroinvertebrate communities. In Calow, P. \& G. E. Petts (eds), The Rivers Handbook, Vol. II. Blackwell Scientific Publications, London, 144-170.

Moore, W. W., 1977. Seasonal succession of algae in a eutrophic stream in southern England. Hydrobiologia 53: 181-192.

Murray-Bligh, J. A. D., M. T. Furse, F. H. Jones, R. J. M. Gunn, R. A. Dines \& J. F. Wright, 1997. Procedure for collecting and analysing macroinvertebrate samples for RIVPACS. Joint publication by the Institute of Freshwater Ecology and the Environment Agency, 162 pp.

Noble, R. \& I. Cowx, 2002. Development, evaluation \& implementation of a standardised fish-based assessment method for the Ecological Status of European rivers - a contribution to the water framework directive (FAME). A report to the European Commission, $100 \mathrm{pp}$.
Norris, R. H., 1994. Rapid biological assessment, natural variability and selecting reference sites. Classification of rivers and environmental health indicators. In Uys, M. C. (ed.), Proceedings of a Joint South African/Australian Workshop, Cape Town, South Africa. Water Research Commission, Report No. TT/63/94: 129-166.

O'Hare, M. T., A. Baattrup-Pedersen, R. Nijboer, K. Szoszkiewicz \& T. Ferreira, 2006. Macrophyte communities of European streams with altered physical habitat. Hydrobiologia 566: 197-210.

Pinto, P., M. Morais, M. Ilhéu \& L. Sandin, 2006. Relationships among biological elements (macrophytes, macroinvertebrates and ichyofauna) for different river types across Europe at two different spatial scales. Hydrobiologia 566: 75-90.

Raven, P. J., N. T. H. Holmes, F. H. Dawson, P. J. A. Fox, M. Everard, I. R. Fozzard \& K. J. Rouen, 1998. River Habitat Quality - The Physical Character of Rivers and Streams in the UK and Isle of Man. River Habitat Survey Report Number 2. Environment Agency, Bristol: Scottish Environment Protection Agency, Stirling: Environment and Heritage Service, Belfast, $1-84$

Reynoldson, T. B., R. C. Bailey, K. E. Day \& R. H. Norris, 1995. Biological guidelines for freshwater sediment based on BEnthic Assessment of SedimenT (the BEAST) using a multivariate approach for predicting biological state. Australian Journal of Ecology 20: 198-219.

Reynoldson, T. B., K. E. Day \& T. Pascoe, 2000. The development of the BEAST: a predictive approach for assessing sediment quality in the Great Lakes. In Wright, J. F., D. W. Sutcliffe \& M. T. Furse (eds), Assessing the Biological Quality of Freshwaters: RIVPACS and Similar Techniques. Freshwater Biological Association, Ambleside, 165-180.

Rosenberg, D. M., T. B. Reynoldson \& V. H. Resh, 2000. Establishing reference conditions in the Fraser River catchment, British Colombia, Canada, using the BEAST (Benthic Assessment of SedimenT) predictive model. In Wright, J. F., D. W. Sutcliffe \& M. T. Furse (eds), Assessing the Biological Quality of Freshwaters: RIVPACS and Similar Techniques. Freshwater Biological Association, Ambleside, 181-194.

Schmidt-Kloiber, A., W. Graf, A. Lorenz \& O. Moog, 2006. The AQEM/STAR taxalist - a pan-European macro-invertebrate ecological database and taxa inventory. Hydrobiologia 566: 325-342.

Seber, G. A. F. \& E. D. Le Cren, 1967. Estimating population parameters from catches large relative to the population. Journal of Animal Ecology 36: 631-643.

Sladecek, V., 1973. System of water quality from the biological point of view. Archiv für Hydrobiologie Ergebnisse der Limnologie 7: 1-218.

Šporka, F., H. E. Vlek, E. Bulánková \& I. Krno, 2006. Influence of seasonal variation on bioassessment of streams using macroinvertebrates. Hydrobiologia 566: 543-555.

Springe, G., L. Sandin, A. Briede \& A. Skuja, 2006. Biological quality metrics: their variability and appropriate scale for assessing streams. Hydrobiologia 566: 153-172.

Staniszewski, R., K. Szoszkiewicz, J. Zbierska, J. Lesny, S. Jusik \& R. T. Clarke, 2006. Assessment of sources of uncertainty in macrophyte surveys and the consequences for river classification. Hydrobiologia 566: 235-246. 
Swedish Environmental Protection Agency, 1996. Bottenfauna i sjöars litoral och I vattendrag - tidsserier. [In Swedish: Benthic fauna in lake litoral and running waters - time series]. Swedish EPA monitoring handbook, Fresh waters. [Published digitally at: www.naturvardsverket.se].

Szoszkiewicz, K., A. Buffagni, J. Davy-Bowker, J. Lesny, B. H. Chojnicki, J. Zbierska, R. Staniszewski \& T. Zgola, 2006a. Occurrence and variability of River Habitat Survey features across Europe and the consequences for data collection and evaluation. Hydrobiologia 566: 267-280.

Szoszkiewicz, K., T. Ferreira, T. Korte, A. Baattrup-Pedersen, J. Davy-Bowker \& M. O'Hare, 2006b. European river plant communities: the importance of organic pollution and the usefulness of existing macrophyte metrics. Hydrobiologia 566: 211-234.

Verdonschot, P. F. M., 2006a. Evaluation of the use of Water Framework Directive typology descriptors, reference sites and spatial scale in macroinvertebrate stream typology. Hydrobiologia 566: 39-58.
Verdonschot, P. F. M., 2006b. Data composition and taxonomic resolution in macroinvertebrate stream typology. Hydrobiologia 566: 59-74.

Vlek, H. E., F. Šporka \& I. Krno, 2006. Influence of macroinvertebrate sample size on bioassessment of streams. Hydrobiologia 566: 523-542.

Winter, J. G. \& H. C. Duthie, 2000. Stream epilithic, epipelic and epiphytic diatoms: habitat fidelity and use in biomonitoring. Aquatic Ecology 34: 345-353.

Wright, J. F., P. D. Armitage \& M. T. Furse, 1989. Prediction of invertebrate communities using stream measurements. Regulated Rivers: Research and Management 4: 147-155.

Wright, J. F., D. W. Sutcliffe \& M. T. Furse (eds), 2000. Assessing the Biological Quality of Freshwaters: RIVPACS and Similar Techniques. Freshwater Biological Association, Ambleside. 